\title{
Cervical assessment by ultrasound for preventing preterm delivery.
}

Vincenzo Berghella

Thomas Jefferson University

Jason K. Baxter MD, MSCP

Department of Obstetrics and Gynecology, Thomas Jefferson University

Nancy W Hendrix

Division of Maternal-Fetal Medicine, Department of Obstetrics and Gynecology, Jefferson Medical College of Thomas Jefferson University

Follow this and additional works at: https://jdc.jefferson.edu/obgynfp

Part of the Obstetrics and Gynecology Commons

Let us know how access to this document benefits you

\section{Recommended Citation}

Berghella, Vincenzo; Baxter, Jason K. MD, MSCP; and Hendrix, Nancy W, "Cervical assessment by ultrasound for preventing preterm delivery." (2013). Department of Obstetrics and Gynecology Faculty Papers. Paper 29.

https://jdc.jefferson.edu/obgynfp/29

This Article is brought to you for free and open access by the Jefferson Digital Commons. The Jefferson Digital Commons is a service of Thomas Jefferson University's Center for Teaching and Learning (CTL). The Commons is a showcase for Jefferson books and journals, peer-reviewed scholarly publications, unique historical collections from the University archives, and teaching tools. The Jefferson Digital Commons allows researchers and interested readers anywhere in the world to learn about and keep up to date with Jefferson scholarship. This article has been accepted for inclusion in Department of Obstetrics and Gynecology Faculty Papers by an authorized administrator of the Jefferson Digital Commons. For more information, please contact:

JeffersonDigitalCommons@jefferson.edu. 


\title{
Cervical assessment by ultrasound for preventing preterm delivery (Review)
}

\author{
Berghella V, Baxter JK, Hendrix NW
}

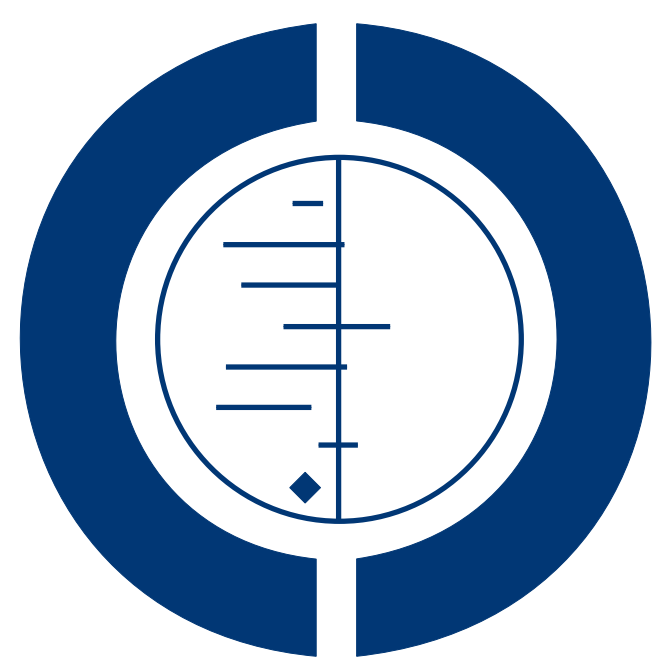

THE COCHRANE
COLLABORATION $^{\circledR}$

This is a reprint of a Cochrane review, prepared and maintained by The Cochrane Collaboration and published in The Cochrane Library 2013, Issue 1

http://www.thecochranelibrary.com

\section{WILEY}

Cervical assessment by ultrasound for preventing preterm delivery (Review)

Copyright $\odot 2013$ The Cochrane Collaboration. Published by John Wiley \& Sons, Ltd. 
TABLE OF CONTENTS

HEADER . . . . . . . . . . . . . . . . . . . . . . . . . . . . . . . . . . . . . . . . . . . . . . . . . . . . . .

ABSTRACT . . . . . . . . . . . . . . . . . . . . . . . . . . . . . . . . . . . . . . . . . . . . . . . . . .

PLAIN LANGUAGE SUMMARY . . . . . . . . . . . . . . . . . . . . . . . . . . . . . . . . . . . . . . . . . . .

BACKGROUND . . . . . . . . . . . . . . . . . . . . . . . . . . . . . . . . . . . . . 2

OBJECTIVES . . . . . . . . . . . . . . . . . . . . . . . . . . . . . . . . . . . . . . . . . . . . . . .

METHODS . . . . . . . . . . . . . . . . . . . . . . . . . . . . . . . . . . . . . . . 3

RESUlTS . . . . . . . . . . . . . . . . . . . . . . . . . . . . . . . . . . . . . . . . . . . .

Figure 1. . . . . . . . . . . . . . . . . . . . . . . . . . . . . . . . . . . . . . . . . . .

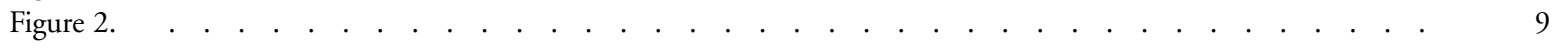

DISCUSSION . . . . . . . . . . . . . . . . . . . . . . . . . . . . . . . . . . . . . . . . . 11

AUTHORS' CONCLUSIONS . . . . . . . . . . . . . . . . . . . . . . . . . . . . . . . . . . . . . . . . .

ACKNOWLEDGEMENTS . . . . . . . . . . . . . . . . . . . . . . . . . . . . . . . . . . . . . . . .

REFERENCES . . . . . . . . . . . . . . . . . . . . . . . . . . . . . . . . . . . . . . 12

CHARACTERISTICS OF STUDIES . . . . . . . . . . . . . . . . . . . . . . . . . . . . . . . . . . . . . . . . . . .

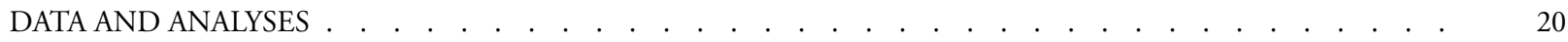

Analysis 1.1. Comparison 1 TVU CL knowledge versus no knowledge (asymptomatic twins without PTL or PPROM),

Outcome 1 Preterm birth < 36 weeks.

Analysis 1.2. Comparison 1 TVU CL knowledge versus no knowledge (asymptomatic twins without PTL or PPROM), Outcome 2 Preterm birth $<34$ weeks.

Analysis 1.3. Comparison 1 TVU CL knowledge versus no knowledge (asymptomatic twins without PTL or PPROM), Outcome 3 Preterm birth $<32$ weeks.

Analysis 1.4. Comparison 1 TVU CL knowledge versus no knowledge (asymptomatic twins without PTL or PPROM), Outcome 4 Preterm birth $<30$ weeks.

Analysis 1.5. Comparison 1 TVU CL knowledge versus no knowledge (asymptomatic twins without PTL or PPROM), Outcome 5 Gestational age at delivery.

Analysis 1.6. Comparison 1 TVU CL knowledge versus no knowledge (asymptomatic twins without PTL or PPROM), Outcome 6 Birthweight.

Analysis 1.7. Comparison 1 TVU CL knowledge versus no knowledge (asymptomatic twins without PTL or PPROM), Outcome 7 Maternal hospitalization (PTL).

Analysis 1.8. Comparison 1 TVU CL knowledge versus no knowledge (asymptomatic twins without PTL or PPROM), Outcome 8 Tocolysis.

Analysis 1.9. Comparison 1 TVU CL knowledge versus no knowledge (asymptomatic twins without PTL or PPROM), Outcome 9 Steroids for fetal lung maturity.

Analysis 2.1. Comparison 2 TVU CL knowledge versus no knowledge (symptomatic singletons with PTL), Outcome 1 Preterm birth $<37$ weeks. . . . . . . . . . . . . . . . . . . . . . . . . . . . . . . .

Analysis 2.2. Comparison 2 TVU CL knowledge versus no knowledge (symptomatic singletons with PTL), Outcome 2 Preterm birth $<34$ weeks. . . . . . . . . . . . . . . . . . . . . . . . . . . . . . . . . . . . . . . . .

Analysis 2.3. Comparison 2 TVU CL knowledge versus no knowledge (symptomatic singletons with PTL), Outcome 3 Preterm birth $<28$ weeks. . . . . . . . . . . . . . . . . . . . . . . . . . . . . . . . . . . . . . . . .

Analysis 2.4. Comparison 2 TVU CL knowledge versus no knowledge (symptomatic singletons with PTL), Outcome 4

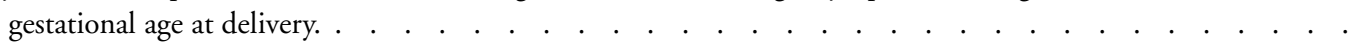

Analysis 2.5. Comparison 2 TVU CL knowledge versus no knowledge (symptomatic singletons with PTL), Outcome 5 Birthweight $<2500$ grams.

Analysis 2.6. Comparison 2 TVU CL knowledge versus no knowledge (symptomatic singletons with PTL), Outcome 6 Perinatal death.

Analysis 2.7. Comparison 2 TVU CL knowledge versus no knowledge (symptomatic singletons with PTL), Outcome 7 Maternal hospitalization. . . . . . . . . . . . . . . . . . . . . . . . . . . . . . . . . . . . . . .

Analysis 2.8. Comparison 2 TVU CL knowledge versus no knowledge (symptomatic singletons with PTL), Outcome 8 Tocolysis.

Analysis 2.9. Comparison 2 TVU CL knowledge versus no knowledge (symptomatic singletons with PTL), Outcome 9

Steroids for fetal lung maturity. . . . . . . . . . . . . . . . . . . . . . . . . . . . . . . . . . . . . . . . . 
Analysis 3.1. Comparison 3 TVU CL knowledge versus no knowledge (symptomatic singletons with PPROM), Outcome

1 Birthweight $<2500$ grams.

Analysis 3.2. Comparison 3 TVU CL knowledge versus no knowledge (symptomatic singletons with PPROM), Outcome

2 Chorioamnionitis.

Analysis 3.3. Comparison 3 TVU CL knowledge versus no knowledge (symptomatic singletons with PPROM), Outcome

3 Endometritis.

Analysis 3.4. Comparison 3 TVU CL knowledge versus no knowledge (symptomatic singletons with PPROM), Outcome

4 Neonatal infection. . . . . . . . . . . . . . . . . . . . . . . . . . . . . . . . 33

APPENDICES . . . . . . . . . . . . . . . . . . . . . . . . . . . . . . . . . . . . . . . . . . .

WHAT'S NEW . . . . . . . . . . . . . . . . . . . . . . . . . . . . . . . . . . . . . . . . . . .

HISTORY . . . . . . . . . . . . . . . . . . . . . . . . . . . . . . . . . . . . . . . . . . .

CONTRIBUTIONS OF AUTHORS . . . . . . . . . . . . . . . . . . . . . . . . . . . . . . . . . . . . .

DECLARATIONS OF INTEREST . . . . . . . . . . . . . . . . . . . . . . . . . . . . . . . . . . . . . 36

SOURCES OF SUPPORT . . . . . . . . . . . . . . . . . . . . . . . . . . . . . . . . . . . . . . . . . . . .

DIFFERENCES BETWEEN PROTOCOL AND REVIEW . . . . . . . . . . . . . . . . . . . . . . . . . . . . 36

INDEX TERMS . . . . . . . . . . . . . . . . . . . . . . . . . . . . . . . . . . . . . . . . . . . . . . . . 


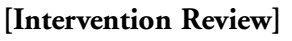 \\ Cervical assessment by ultrasound for preventing preterm delivery
}

\author{
Vincenzo Berghella ${ }^{1}$, Jason K Baxter ${ }^{1}$, Nancy W Hendrix ${ }^{2}$ \\ ${ }^{1}$ Division of Maternal-Fetal Medicine, Department of Obstetrics and Gynecology, Jefferson Medical College of Thomas Jefferson \\ University, Philadelphia, Pennsylvania, USA. ${ }^{2}$ Department of Obstetrics and Gynecology, Thomas Jefferson University, Philadelphia, \\ PA, USA \\ Contact address: Vincenzo Berghella, Division of Maternal-Fetal Medicine, Department of Obstetrics and Gynecology, Jefferson \\ Medical College of Thomas Jefferson University, 834 Chestnut Street, Suite 400, Philadelphia, Pennsylvania, PA 19107, USA. \\ vincenzo.berghella@jefferson.edu.
}

Editorial group: Cochrane Pregnancy and Childbirth Group.

Publication status and date: Edited (no change to conclusions), published in Issue 2, 2013.

Review content assessed as up-to-date: 28 November 2012.

Citation: Berghella V, Baxter JK, Hendrix NW. Cervical assessment by ultrasound for preventing preterm delivery. Cochrane Database of Systematic Reviews 2013, Issue 1. Art. No.: CD007235. DOI: 10.1002/14651858.CD007235.pub3.

Copyright (C) 2013 The Cochrane Collaboration. Published by John Wiley \& Sons, Ltd.

\begin{abstract}
A B S T R A C T
Background

Measurement of cervical length (CL) by transvaginal ultrasound (TVU) is predictive of preterm birth (PTB). It is unclear if this screening test is effective for prevention of PTB.
\end{abstract}

\section{Objectives}

To assess the effectiveness of antenatal management based on transvaginal ultrasound of cervical length (TVU CL) screening for preventing PTB.

\section{Search methods}

We searched the Cochrane Pregnancy and Childbirth Group's Trials Register (31 August 2012), reviewed the reference lists of all articles and contacted experts in the field for additional and ongoing trials.

\section{Selection criteria}

Published and unpublished randomized controlled trials including pregnant women between the gestational ages of 14 to 32 weeks screened with TVU CL for risk of PTB. This review focuses exclusively on studies based on knowledge versus no knowledge of TVU CL results.

\section{Data collection and analysis}

All potential studies identified from the search were independently assessed for inclusion by three review authors. We also analyzed studies for quality measures and extracted data.

\section{Main results}

Of the 13 trials identified, five were eligible for inclusion $(\mathrm{n}=507)$. Three included singleton gestations with preterm labor (PTL); one included singleton gestations with preterm premature rupture of membranes (PPROM); and one included twin gestations with or without PTL.

Cervical assessment by ultrasound for preventing preterm delivery (Review)

Copyright @ 2013 The Cochrane Collaboration. Published by John Wiley \& Sons, Ltd. 
In the three trials of singleton gestations with PTL, 290 women were randomized; 147 to knowledge and 143 to no knowledge of TVU CL. Knowledge of TVU CL results was associated with a non-significant decrease in PTB at less than 37 weeks (22.3\% versus $34.7 \%$, respectively; average risk ratio $0.59,95 \%$ confidence interval (CI) 0.26 to 1.32 ; two trials, 242 women) and at less than 34 weeks (6.9\% verus $12.6 \%$; RR 0.55 , 95\% CI 0.25 to 1.20 ; three trials, 256 women). Delivery occurred at a later gestational age in the knowledge versus no knowledge groups (mean difference (MD) 0.64 weeks, $95 \%$ CI 0.03 to 1.25; three trials, 290 women). For all other outcomes for which there were available data (PTB at less than 34 or 28 weeks; birthweight less than 2500 grams; perinatal death; maternal hospitalization; tocolysis; and steroids for fetal lung maturity), there was no evidence of a difference between groups.

The trial of singleton gestations with PPROM $(n=92)$ evaluated as its primary outcome safety of TVU CL in this population, and not its effect on management. There was no evidence of a difference in incidence of maternal and neonatal infections between the TVU CL and no TVU CL groups.

In the trial of twin gestations with or without PTL $(\mathrm{n}=125)$, there was no evidence of a difference in PTB at less than 36, 34, or 30 weeks, gestational age at delivery, and other perinatal and maternal outcomes between the TVU CL and the no TVU CL groups. Lifetable analysis revealed significantly less PTB at less than 35 weeks in the TVU CL group compared with the no TVU CL group (P = $0.02)$.

\section{Authors' conclusions}

Currently, there is insufficient evidence to recommend routine screening of asymptomatic or symptomatic pregnant women with TVU CL. Since there is a non-significant association between knowledge of TVU CL results and a lower incidence of PTB at less than 37 weeks in symptomatic women, we encourage further research. Future studies should look at specific populations separately (e.g., singleton versus twins; symptoms of PTL or no such symptoms), report on all pertinent maternal and perinatal outcomes, and include cost-effectiveness analyses. Most importantly, future studies should include a clear protocol for management of women based on TVU CL results, so that it can be easily evaluated and replicated.

\section{PLAIN LANGUAGE SUMMARY}

\section{Cervical assessment by ultrasound for preventing preterm delivery}

Preterm birth before 37 weeks is the main cause of death and disability for neonates. The lower part of the uterus, called the cervix, is the opening or passage through which births, including preterm, occur. Ultrasound performed through the vagina can detect early changes of the cervix that predict preterm birth. This review assessed if knowledge of such changes can prevent preterm birth. Of the 13 trials identified, five (507 women) were eligible for inclusion. Currently, the studies reported are insufficient to recommend ultrasound of the cervix for prevention of preterm birth. Since there is a tendency for knowledge of the results of the cervical ultrasound to be associated with a lower chance of preterm birth in women who have uterine contractions and preterm labor, further research should be encouraged.

\section{B A C K G R O U N D}

\section{Description of the condition}

Preterm birth (PTB) is defined by the World Health Organization as birth between 20 and 36 6/7 weeks. PTB can be spontaneous, and follow preterm labor (PTL) (50\%), or preterm premature rupture of membranes (PPROM) (30\%). It can also be iatrogenic (caused by health worker intervention) (20\%). Its incidence is about $5 \%$ to $8 \%$ in most developed and developing countries. This incidence is increasing in many countries, including developing countries, despite extensive research efforts. It was $12 . \%$ in 2010 in the USA, representing more than 500,000 PTBs annually in the USA alone (National Vital Statistics Report 2011). Some of the reasons may include increases in the incidence of multiple gestations, assisted reproductive technologies, better dating and recording of gestational age, more fetal monitoring and iatrogenic deliveries, etc. PTB is the main cause of neonatal morbidity and 
mortality in most countries, especially in developed countries. In the USA, $75 \%$ of perinatal mortality occurs in preterm babies; $60 \%$ of total perinatal mortality occurs in infants born before 32 weeks. Mortality and morbidities are inversely associated with gestational age at birth. Morbidities include respiratory distress syndrome, bronchopulmonary dysplasia, intraventricular hemorrhage, necrotizing enterocolitis, sepsis, retinopathy, etc. The whole family suffers greatly in several aspects when a baby has been born prematurely, including medically, socially, psychologically, and financially.

\section{Description of the intervention}

Most of the interventions studied have been aimed at tertiary prevention, i.e., prevention once symptoms (e.g., PTL or PPROM) develop. Interventions based on risk factors, usually based on prior history, have generally been unsuccessful. Recently, a screening test, cervical ultrasound, has been associated with better prediction of PTB than previously available tests, and interventions based on this screening test have been tested in randomized trials.

\section{How the intervention might work}

Cervical assessment by ultrasound has been correlated with the prediction of spontaneous PTB (Berghella 2003). There are three methods of ultrasound cervical assessment: transvaginal (TVU), transabdominal (TA), and transperineal (TP, also called translabial). The most objective and effective ultrasound method is transvaginal (TVU) (Hernandez-Andrade 2012). When TA ultrasound screening of cervical length (CL) has been compared with TVU for prediction of PTB, most women detected to have a short $\mathrm{Cl}$ by TVU were not detected by TA ultrasound (Hernandez-Andrade 2012), so that most literature is the result of the more predictive TVU screening. The most predictive and reproducible variable that can be measured on TVU is CL. The gestational age at which TVU CL is most predictive of PTB is 14 to 34 weeks, but shortening at earlier and later gestational ages is also associated with PTB. The shorter the CL, the higher the risk of PTB becomes (Grimes-Dennis 2007). The earlier in gestation the shortening is detected, the higher the risk of PTB (Berghella 2007). This prediction has been confirmed in all populations screened with transvaginal ultrasound of cervical length (TVU CL) so far, including singleton and multiple gestations, women with or without risk factors (e.g., prior PTB, mullerian anomalies, cervical surgery, etc.) for PTB, asymptomatic women as well as those with PTL or PPROM (Grimes-Dennis 2007). In fact, TVU CL is one of the best predictors of PTB in all populations studied so far. The overall sensitivity and specificity vary according to the CL cutoff used (e.g., $25 \mathrm{~mm}$ versus $15 \mathrm{~mm}$ ); gestational age at screening; population studied; prevalence of PTB; single versus serial screening; etc. Its positive predictive value also varies depending on the incidence of PTL in the population studied. The intervention of CL assessment by ultrasound has been studied in combination with other interventions (e.g. cerclage, progesterone, pessary, etc) for prevention of PTB, and the reader is encouraged to read these specific Cochrane Reviews. (e.g., progesterone (Dodd 2006), cerclage (Alfirevic 2012; Rafael 2011); or pessary (Abdel-Aleem 2010)).Knowledge of CL assessment by ultrasound per se can also be considered an intervention, and is the topic of this review. In addition, CL assessment could also reduce other intervention (e.g. activity restriction, tocolytics, steroids, etc).

\section{Why it is important to do this review}

PTB is the main cause of neonatal morbidity and mortality in most countries, especially in developed countries. In the USA, $75 \%$ of perinatal mortality occurs in preterm babies; $60 \%$ of total perinatal mortality occurs in infants born before 32 weeks. Mortality and morbidities are inversely associated with gestational age at birth. Morbidities include respiratory distress syndrome, bronchopulmonary dysplasia, intraventricular hemorrhage, necrotizing enterocolitis, sepsis, retinopathy, etc. The whole family suffers greatly in several aspects when a baby has been born prematurely, including medically, socially, psychologically, and financially.

\section{O B J E C T I VES}

To assess the effectiveness of antenatal management based on transvaginal ultrasound cervical length screening for preventing preterm birth.

\section{METHODS}

\section{Criteria for considering studies for this review}

\section{Types of studies}

Published and unpublished randomized controlled trials. We planned to include cluster-randomized and quasi-randomized trials, if available.

\section{Types of participants}

Pregnant women between the gestational ages of 14 to 34 weeks screened with transvaginal ultrasound (TVU) and/or transabdominal ultrasound (TA) cervical length (CL) for risk of preterm birth. Given the different characteristics of singleton versus twin gestations, women with asymptomatic versus symptomatic 
(preterm labor (PTL) or preterm premature rupture of membranes (PPROM)), and PTL versus PPROM, comparisons were divided into:

- asymptomatic singletons;

- asymptomatic twins;

- symptomatic singletons with PTL;

- symptomatic singleton with PPROM;

- symptomatic twins with PTL;

- symptomatic twins with PPROM.

The analysis was also divided by the type of CL ultrasound screening, i.e. TA versus TVU. We carried out analysis of other participants by type of population, as described under 'subgroup analyses'.

\section{Types of interventions}

A screening test such as TVU CL/TA can only be considered effective if the interventions based on screening results reduce the outcome of preterm birth. For this review, screening TVU CL/TA modalities on which interventions were based were:

- knowledge versus no knowledge of TVU CL/TA results (i.e., TVU CL/TA is performed on all women, but women are randomized so that in about $50 \%$ of them the result is available to the managing obstetrician, while in about $50 \%$ the managing obstetrician is blind to the TVU CL/TA result); or TVU CL/TA versus no TVU CL/TA (TVU CL/TA screening is only performed on half of the women).

\section{Types of outcome measures}

\section{Primary outcomes}

1. Preterm birth (less than 37 weeks for singleton gestations; less than 34 weeks for twin gestations)

\section{Secondary outcomes}

1. Preterm birth (less than 36 weeks) (outcome not prespecified)

2. Preterm birth (less than 34 weeks)

3. Preterm birth (less than 30 weeks) (outcome not prespecified)

4. Preterm birth (less than 32 weeks)

5. Preterm birth (less than 28 weeks)

6. Gestational age at delivery

7. Birthweight less than 2500 grams

8. Birthweight (outcome not prespecified)

9. Composite perinatal outcome (perinatal death, respiratory distress syndrome, intraventricular hemorrhage, necrotizing enterocolitis, and sepsis)

10. Perinatal death (fetal death and neonatal death)
11. Fetal death

12. Neonatal death

13. Neonatal infection (outcome not prespecified)

14. Respiratory distress syndrome

15. Intraventricular hemorrhage

16. Necrotizing enterocolitis

17. Sepsis

18. Neonatal intensive care unit (NICU) admission

19. NICU days

20. Maternal hospitalization

21. Maternal wellbeing (e.g., stress level, etc)

22. Economic analysis (cost effectiveness, cost utility)

23. Tocolysis

24. Cervical cerclage

25. Steroids

26. Chorioamnionitis (outcome not prespecified)

27. Endometritis (outcome not prespecified)

\section{Search methods for identification of studies}

\section{Electronic searches}

We searched the Cochrane Pregnancy and Childbirth Group's Trials Register by contacting the Trials Search Co-ordinator (31 August 2012).

The Cochrane Pregnancy and Childbirth Group's Trials Register is maintained by the Trials Search Co-ordinator and contains trials identified from:

1. monthly searches of the Cochrane Central Register of Controlled Trials (CENTRAL);

2. weekly searches of MEDLINE;

3. weekly searches of EMBASE;

4. handsearches of 30 journals and the proceedings of major conferences;

5. weekly current awareness alerts for a further 44 journals plus monthly BioMed Central email alerts.

Details of the search strategies for CENTRAL, MEDLINE and EMBASE, the list of handsearched journals and conference proceedings, and the list of journals reviewed via the current awareness service can be found in the 'Specialized Register' section within the editorial information about the Cochrane Pregnancy and Childbirth Group.

Trials identified through the searching activities described above are each assigned to a review topic (or topics). The Trials Search Co-ordinator searches the register for each review using the topic list rather than keywords.

For details of additional searching carried out for the initial version of the review, please see Appendix 1. 


\section{Searching other resources}

We reviewed the reference list of all articles, in particular trials and review articles. If necessary, we contacted researchers to provide further information. We contacted experts in the field for additional and ongoing trials.

We did not apply any language restrictions.

\section{Data collection and analysis}

For the methods used when assessing the trials identified in the previous version of this review, see Appendix 2.

\section{Selection of studies}

We assessed for inclusion all potential studies we identified as a result of the search strategy. Independently, all three review authors (V Berghella (VB), N Hendrix (NH), and JK Baxter (JB)) assessed all studies for inclusion in the review using the inclusion criteria. We resolved any disagreement through discussion.

\section{Data extraction and management}

We designed a form to extract data. Three authors (VB, NH, JB) extracted the data using the agreed form. We resolved any disagreement through discussion. We used the Review Manager software (RevMan 2011) to double enter all the data or a subsample. When information regarding any of the above was unclear, or to obtain additional data not published, we attempted to contact authors of the original reports to provide further details.

\section{Assessment of risk of bias in included studies}

We have assessed the validity of each study using the criteria outlined in the Cochrane Handbook for Systematic Reviews of Interventions (Higgins 2011). We resolved any disagreement by discussion.

\section{(I) Random sequence generation (checking for possible selection bias)}

We described for each included study the method used to generate the allocation sequence in sufficient detail to allow an assessment of whether it should produce comparable groups.

We have assessed the method as:

- low risk of bias (any truly random process e.g., random number table; computer random number generator);

- high risk of bias (any non-random process e.g., odd or even date of birth; hospital or clinic record number);

- unclear risk of bias.
(2) Allocation concealment (checking for possible selection bias)

We described for each included study the method used to conceal allocation to interventions prior to assignment and determined whether intervention allocation could have been foreseen in advance of, or during recruitment, or changed after assignment. We assessed the methods as:

- low risk of bias (e.g., telephone or central randomization; consecutively numbered sealed opaque envelopes);

- high risk of bias (open random allocation; unsealed or nonopaque envelopes, alternation; date of birth);

- unclear risk of bias.

\section{(3.I) Blinding of participants and personnel (checking for possible performance bias)}

We described for each included study the methods used, if any, to blind study participants and personnel from knowledge of which intervention a participant received. We considered that studies were at low risk of bias if they were blinded, or if we judged that the lack of blinding would be unlikely to affect results. We assessed blinding separately for different outcomes or classes of outcomes. We assessed the methods as:

- low, high or unclear risk of bias for participants;

- low, high or unclear risk of bias for personnel.

\section{(3.2) Blinding of outcome assessment (checking for possible detection bias)}

We described for each included study the methods used, if any, to blind outcome assessors from knowledge of which intervention a participant received. We assessed blinding separately for different outcomes or classes of outcomes. We assessed methods used to blind outcome assessment as:

- low, high or unclear risk of bias.

(4) Incomplete outcome data (checking for possible attrition bias through withdrawals, dropouts, protocol deviations)

We described for each included study, and for each outcome or class of outcomes, the completeness of data, including attrition and exclusions from the analysis. We stated whether attrition and exclusions were reported, the numbers included in the analysis at each stage (compared with the total randomized participants), reasons for attrition or exclusion where reported, and whether missing data were balanced across groups or were related to outcomes. Where sufficient information has been reported, or been supplied by the trial authors, we have re-included missing data in our analyses.

We assessed methods as:

- low risk of bias (less than 20\%);

- high risk of bias (greater than or equal to $20 \%$ ); 
- unclear risk of bias.

\section{(5) Selective reporting bias}

We described for each included study how we investigated the possibility of selective outcome reporting bias and what we found. We assessed the methods as:

- low risk of bias (where it is clear that all of the study's prespecified outcomes and all expected outcomes of interest to the review have been reported);

- high risk of bias (where not all the study's prespecified outcomes have been reported; one or more reported primary outcomes were not prespecified; outcomes of interest are reported incompletely and so cannot be used; study fails to include results of a key outcome that would have been expected to have been reported);

- unclear risk of bias.

\section{6) Other bias (checking for bias due to problems not covered by (I) to (5) above)}

We described for each included study any important concerns we had about other possible sources of bias.

We assessed whether each study was free of other problems that could put it at risk of bias:

- low risk of other bias;

- high risk of other bias;

- unclear whether there is risk of other bias.

\section{(7) Overall risk of bias}

We made explicit judgements about whether studies were at high risk of bias, according to the criteria given in the Handbook (Higgins 2011). With reference to (1) to (6) above, we assessed the likely magnitude and direction of the bias and whether we considered it likely to impact on the findings. We planned to explore the impact of the level of bias through undertaking sensitivity analyses - see Sensitivity analysis.

\section{Measures of treatment effect}

We carried out statistical analysis using the Review Manager software (RevMan 2011). We used fixed-effect meta-analysis for combining data in the absence of significant heterogeneity if trials were sufficiently similar. If heterogeneity was found, we explored this by sensitivity analysis, followed by random-effects analysis if required.

\section{Dichotomous data}

For dichotomous data, we presented results as summary risk ratio with $95 \%$ confidence intervals.

\section{Continuous data}

For continuous data, we used the mean difference if outcomes were measured in the same way between trials. We planned to use the standardized mean difference to combine trials that measured the same outcome, but used different methods. If we had found evidence of skewness, we would have reported this.

\section{Unit of analysis issues}

\section{Cluster-randomized trials}

We did not identify any cluster-randomized trials for inclusion in this review, but we may include trials of this type in future updates. If we do, we plan to include cluster-randomized trials in the analyses along with individually-randomized trials. Their sample sizes will be adjusted using the methods described in Gates 2005 using an estimate of the intracluster correlation co-efficient (ICC) derived from the trial (if possible), or from another source. If ICCs from other sources are used, we will report this and conduct sensitivity analyses to investigate the effect of variation in the ICC. If we identify both cluster-randomized trials and individually-randomized trials, we intend to synthesize the relevant information. We consider it reasonable to combine the results from both if there is little heterogeneity between the study designs and the interaction between the effect of intervention and the choice of randomization unit is considered to be unlikely. We will also acknowledged heterogeneity in the randomization unit and perform a separate meta-analysis; therefore, the meta-analysis will be performed in two parts as well if significant heterogeneity is found.

\section{Dealing with missing data}

We analyzed data on all participants with available data in the group to which they were allocated, regardless of whether or not they received the allocated intervention. If in the original reports participants were not analyzed in the group to which they were randomized, and there was sufficient information in the trial report, we attempted to restore them to the correct group.

\section{Assessment of heterogeneity}

We assessed statistical heterogeneity in each meta-analysis using the $\mathrm{T}^{2}, \mathrm{I}^{2}$ and $\mathrm{Chi}^{2}$ statistics. We regarded heterogeneity as substantial if an $\mathrm{I}^{2}$ was greater than $50 \%$ and either the $\mathrm{T}^{2}$ was greater than zero, or there was a low $\mathrm{P}$ value (less than 0.10 ) in the $\mathrm{Chi}^{2}$ test for heterogeneity.

\section{Assessment of reporting biases}

If 10 or more studies had contributed data to meta-analysis for any particular outcome, we planned to investigate reporting biases 
(such as publication bias) using funnel plots. We would have assessed possible asymmetry visually, and used formal tests for funnel plot asymmetry. For continuous outcomes, we would have used the test proposed by Egger 1997, and for dichotomous outcomes, we would have used the test proposed by Harbord 2006. If asymmetry was detected in either of these tests or was suggested by a visual assessment, we planned to perform exploratory analyses to investigate it. In this version of the review, insufficient data were available to allow us to carry out this planned analysis.

\section{Data synthesis}

We carried out statistical analysis using the RevMan software ( RevMan 2011). We used fixed-effect meta-analysis for combining data where it was reasonable to assume that studies were estimating the same underlying treatment effect: i.e., where trials examined the same intervention, and where we judged the trials' populations and methods to be sufficiently similar. If we suspected clinical heterogeneity sufficient to expect the underlying treatment effects to differ between trials, or if substantial statistical heterogeneity was detected, we used random-effects meta-analysis to produce an overall summary provided that we considered an average treatment effect across trials was clinically meaningful.

\section{Subgroup analysis and investigation of heterogeneity}

We planned the following subgroup analyses classifying whole trials by interaction tests as described by Deeks 2001:

- women with low-risk singleton gestations versus high-risk (e.g., prior preterm birth) gestations.

We planned to restrict subgroup analyses to the primary outcomes.

\section{Sensitivity analysis}

We planned to carry out sensitivity analyses to explore the effect of trial quality assessed by concealment of allocation, high attrition rates, or both, with poor quality studies being excluded from the analyses in order to assess whether this made any difference to the overall result.

If quasi-randomized trials are included in future updates, we will perform a sensitivity analysis by trial quality.

\section{R E S U L T S}

\section{Description of studies}

See: Characteristics of included studies; Characteristics of excluded studies.

\section{Results of the search}

Our search identified 13 trials, of which five were eligible for inclusion $(n=507)$. We identified no quasi-randomized trials. All five included studies used transvaginal ultrasound of cervical length (TVU CL) for screening, versus either no TVU CL screening, or no knowledge of results of TVU CL screening. No studies using transabdominal (TA) ultrasound for cervical length screening were identified. Therefore, there were also no trials comparing TV versus TA ultrasound cervical length screening.

\section{Included studies}

The five included studies included: no trials on asymptomatic singletons; one trial on asymptomatic twins without signs and/or symptoms of preterm labor (PTL) (Gordon 2006); three trials on symptomatic women with singleton gestations with signs and/or symptoms of PTL (Alfirevic 2007; Ness 2007; Palacio 2006); one trial on symptomatic women with singleton gestations with signs and/or symptoms of preterm premature rupture of membranes (PPROM) (Carlan 1997); and no trials on symptomatic women with twin gestations with either PTL or PPROM.

We requested patient-level databases from all authors, and obtained them from one trial (Ness 2007).

In the one trial of symptomatic women with twin gestations with or without signs and/or symptoms of PTL, the analysis included 63 women who had TVU CL and 62 who did not.

In the three trials of symptomatic women with singleton gestations with signs and/or symptoms of PTL, 290 women were randomized; 147 were randomized to knowledge and 143 to no knowledge of TVU CL. These numbers were 145 and 142, respectively, after exclusion of twin gestations from the Ness trial. Ness 2007 used knowledge of TVU CL mostly in its protocol for management, but for women with TVU CL 20 to $29 \mathrm{~mm}$, fetal fibronectin (FFN) was used to discriminate management, as well.

In the one trial of symptomatic women with singleton gestations with PPROM, the analysis included 47 women who had TVU $\mathrm{CL}$ and 45 who did not.

\section{Excluded studies}

We excluded three trials because they compared history-indicated to ultrasound-indicated cerclage (Beigi 2005; Kassanos 2001; Shennan 2007); one because the TVU CL information was blinded and not used for management (Matijevic 2006); one because TVU information was not used for clinical care and no data on outcomes were provided (Owen 1999); two because they used transabdominal - not transvaginal - ultrasound (Lorenz 1990; Van Dijken 1991); and one because it used Cervilenz, which measures the vaginal part of the cervix rather than CL (Burwick 2011). 


\section{Risk of bias in included studies}

See Figure 1 and Figure 2 for summaries of 'Risk of bias' assessments.

Figure I. 'Risk of bias' graph: review authors' judgements about each risk of bias item presented as percentages across all included studies.

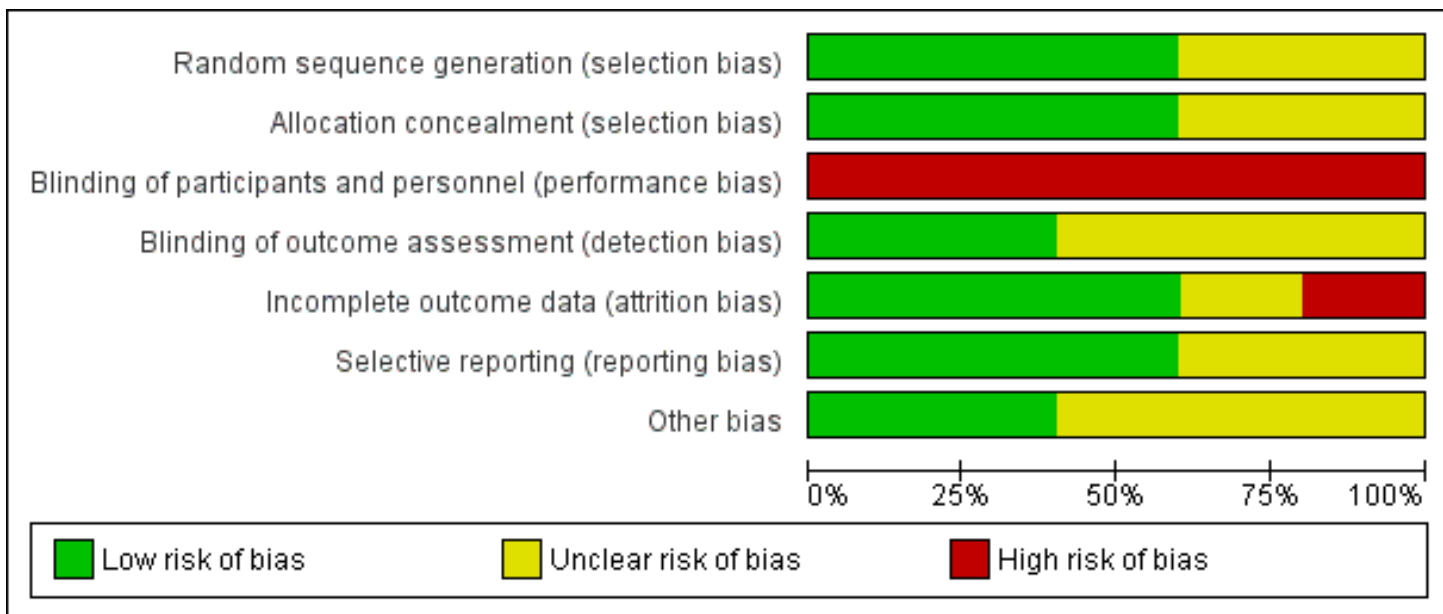


Figure 2. 'Risk of bias' summary: review authors' judgements about each risk of bias item for each included study.

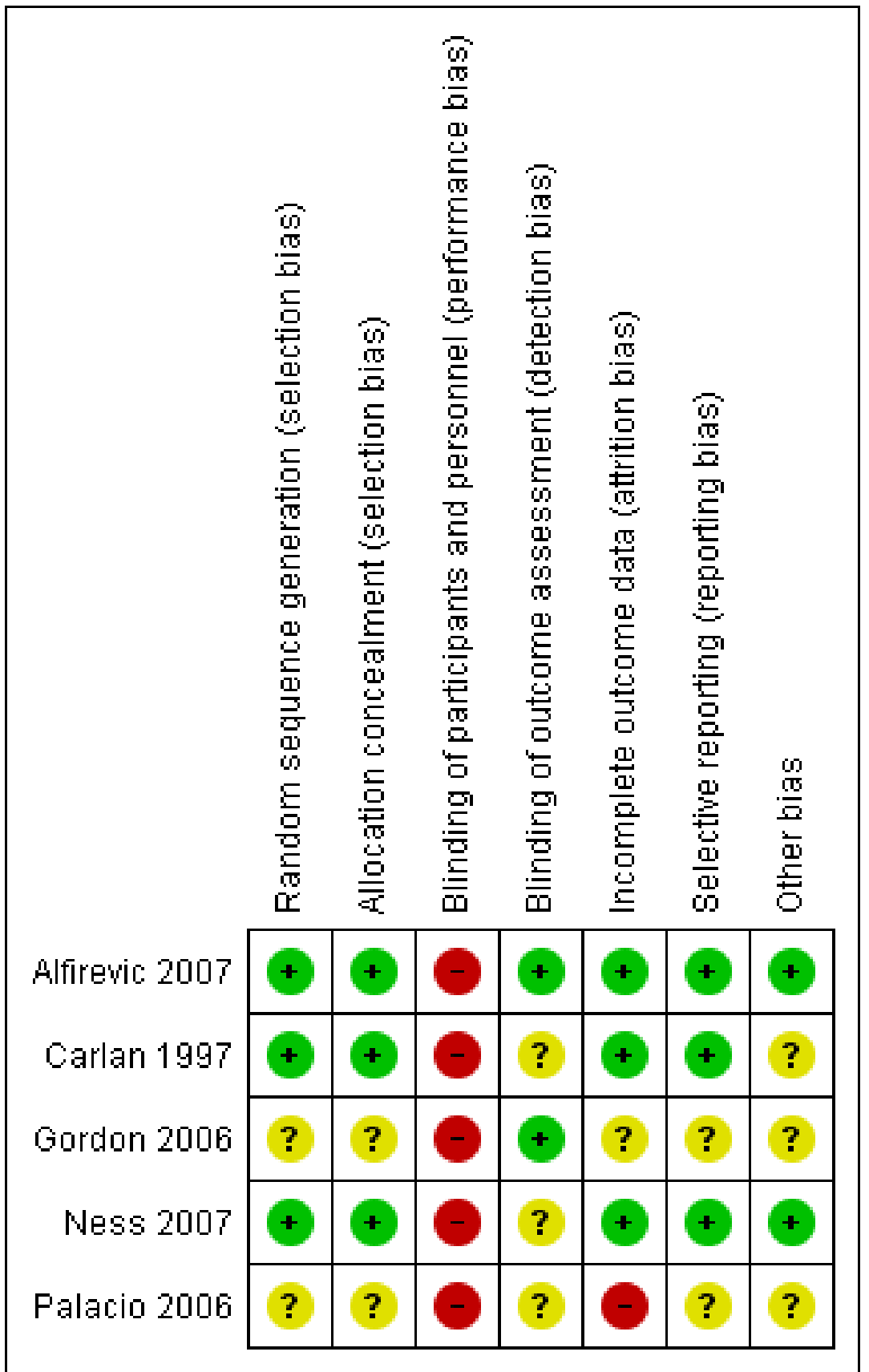




\section{Allocation}

Risk of selection bias was not present in three studies (Alfirevic 2007; Carlan 1997; Ness 2007). The other two studies (Gordon 2006; Palacio 2006) were reported only as abstracts, with no information on methods of randomization or allocation concealment.

\section{Blinding}

Risk of performance bias was present in all trials, as participants and researchers were aware of the arm to which they were randomized, but this was inevitable.

In two trials the primary outcomes were objective measures and so detection bias was assessed as being low risk (Alfirevic 2007; Gordon 2006). It was unclear in other trials if outcome assessment had been blinded (Carlan 1997; Ness 2007; Palacio 2006).

\section{Incomplete outcome data}

Information regarding an intention-to-treat analysis was available for three of the five trials. In two trials (Alfirevic 2007; Ness 2007), all women randomized were included in the intention-to-treat analysis. In Carlan 1997, one out of 93 (1\%) women randomized was excluded from the analysis because she was delivered immediately. Attrition bias in terms of loss of data was present in Palacio 2006, since eight out of 157 (5\%) women randomized were excluded from analysis because they were lost to follow-up, and in Ness 2007, since six out of 100 (6\%) women randomized could not be included in analysis for preterm birth outcomes because they were lost to follow up. It was not possible to assess incomplete outcome data in one trial because the trial was only reported as an abstract and so data were limited (Gordon 2006).

\section{Selective reporting}

Risk of reporting bias was unclear in two trials (Gordon 2006; Palacio 2006) and at low risk of bias in the remaining trials ( Alfirevic 2007; Carlan 1997; Ness 2007).

\section{Other potential sources of bias}

Risk of other potential sources of bias was unclear in three trials, (Carlan 1997; Gordon 2006; Palacio 2006), and at low risk of bias in the remaining two trials (Carlan 1997; Gordon 2006).

\section{Effects of interventions}

\section{TVU CL knowledge versus no knowledge (twins)}

In the one trial of twin gestations with or without signs and/or symptoms of PTL (Gordon 2006), preterm birth less than 36, 34, 32 , or 30 weeks, gestational age at delivery, and other perinatal and maternal outcomes there was no evidence of a difference between the TVU CL and the no TVU CL groups, (Analysis 1.1; Analysis 1.2; Analysis 1.3; Analysis 1.4; Analysis 1.5; Analysis 1.6; Analysis 1.7; Analysis 1.8; Analysis 1.9). Life table analysis revealed significantly less preterm birth at less than 35 weeks in the TVU CL group compared with the no TVU CL group $(\mathrm{P}=0.02)$.

\section{TVU CL knowledge versus no knowledge (singletons with PTL)}

In symptomatic women with singleton gestations with signs and/ or symptoms of PTL, knowledge of TVU CL results was associated with a non-significant decrease in preterm birth at less than 37 weeks compared with no such knowledge (22.3\% versus $34.7 \%$, respectively; average risk ratio (RR) $0.59,95 \%$ confidence interval (CI) 0.26 to 1.32; two trials, 242 women; heterogeneity: $\mathrm{Tau}^{2}=$ $\left.0.23 ; \mathrm{Chi}^{2}=2.90, \mathrm{df}=1(\mathrm{P}=0.09) ; \mathrm{I}^{2}=66 \%\right)$, Analysis 2.1 . Delivery occurred at a later gestational age in the knowledge versus no knowledge groups (mean difference (MD) 0.64 weeks, 95\% CI 0.03 to 1.25 ; three trials, 290 women)), Analysis 2.4. These results were mostly determined by the Ness 2007 trial, which used FFN to determine management in women with TVU CL of 20 to $29 \mathrm{~mm}$. Knowledge of TVU CL results was also associated with a non-significant decrease in preterm birth at less than 34 weeks compared with no such knowledge (6.9\% versus $12.6 \%$; RR 0.55 , 95\% CI 0.25 to 1.20; three trials, 256 women), Analysis 2.2. All other outcomes for which there were available data (preterm birth less than 28 weeks, Analysis 2.3; birthweight less than 2500 grams, Analysis 2.5; perinatal death, Analysis 2.6; ; tocolysis, Analysis 2.8; and steroids for fetal lung maturity, Analysis 2.9) were similar in the two groups. Appropriateness of treatment in terms of steroids for fetal lung maturity was higher in the knowledge versus the no knowledge group in the one trial that evaluated this outcome ( Alfirevic 2007). No other maternal or fetal outcomes were available for meaningful analysis.

Substantial heterogeneity was present in the analyses of preterm birth at less than 37 weeks, tocolysis, and steroids for fetal lung maturity (Analysis 2.1; Analysis 2.8; Analysis 2.9).

\section{TVU CL knowledge versus no knowledge (singletons with PPROM)}

The one trial of symptomatic women with singleton gestations with PPROM (Carlan 1997) evaluated as its primary outcome safety of TVU CL in this population, and not its effect on management. Incidence of PTB or gestational age at delivery were not reported, while there was no evidence of a difference in birthweight 
less than 2500 grams between the two groups, Analysis 3.1. There was also no evidence of a difference in the incidence of maternal ( $20 \%$ versus $28 \%$ ), Analysis 3.2, and neonatal (20\% versus $17 \%$ ) infections, Analysis 3.4, between the TVU CL and no TVU CL groups.

\section{Subgroup analysis and sensitivity analysis}

Data in the five included trials (Alfirevic 2007; Carlan 1997; Gordon 2006; Ness 2007; Palacio 2006) were not reported separately for low-risk versus high-risk (e.g. prior PTB) women, so that subgroup analysis could not be performed. We did not carry a sensitivity analysis because most meta-analyses included data from only one or two studies.

\section{DISCUSSION}

\section{Summary of main results}

There is limited data on the effect of knowledge of cervical length by ultrasound for preventing preterm birth (PTB). All trials use transvaginal ultrasound of cervical length (TVU CL) for screening, with no trial on transabdominal (TA) ultrasound screening. There are no trials comparing CL by ultrasound in asymptomatic women with singleton gestations without preterm labor (PTL) or preterm premature rupture of membranes (PPROM). The effect of knowledge of TVU CL in the management of asymptomatic women with twin gestation without PTL or PPROM cannot be determined, given that there is just one small trial on this population, (Gordon 2006). Knowledge of TVU CL in management of women with singleton gestations and PTL is not associated with any significant effects in any maternal and perinatal outcomes evaluated, possibly due to the small number of trials. (Alfirevic 2007; Ness 2007; Palacio 2006). The effect of knowledge of TVU CL in the management of symptomatic women with singleton gestations and PPROM cannot be determined, given that there is just one small trial on this population.(Carlan 1997) There are also no trials on symptomatic women with twin gestations with either PTL or PPROM. There is also very limited evidence on how CL assessment by ultrasound could avoid unnecessary interventions (e.g. tocolytics, steroids, etc) in women with a normal CL. Further research is therefore necessary.

\section{Overall completeness and applicability of evidence}

It is unclear which interventions are most efficacious once TVU CL results are known. The one study with the most promising results (Ness 2007) suggested: use of fetal fibronectin (FFN) for management of women with TVU CL of 20 to $29 \mathrm{~mm}$; a protocol of no intervention for women with CL equal to or greater than $30 \mathrm{~mm}$; and intervention with steroids for fetal lung maturity and tocolysis for women with TVU CL less than $20 \mathrm{~mm}$; but these results need to be replicated before widespread implementation. Our review did not include, by design, assessment of effectiveness of interventions based on positive TVU CL screening (short CL), or negative TVU CL screening (normal or long CL). These are listed under the specific intervention (e.g., progesterone (Dodd 2006), cerclage (Alfirevic 2012; Rafael 2011); or pessary (AbdelAleem 2010)).

\section{Quality of the evidence}

The five included randomized studies were all relatively small. Blinding was not possible in these five trials. Three of these trials had a low risk of bias overall.

\section{Potential biases in the review process}

One of the authors of this Cochrane Review (Vincenzo Berghella) is a co-author of one of the included trials (Ness 2007).

\section{Agreements and disagreements with other studies or reviews}

Cervical length may have benefit if associated with a specific intervention. For assessment of effectiveness of interventions based on positive TVU CL screening (short CL), or negative TVU CL screening (normal or long CL), please see under the specific intervention (e.g., progesterone, or cerclage). For example, cerclage performed for a short CL (ultrasound-indicated cerclage) has been shown to be associated with some benefit (Alfirevic 2012).

\section{AUTHORS, CONCLUSIONS}

\section{Implications for practice}

Currently, there is insufficient evidence to recommend routine screening of asymptomatic or symptomatic pregnant women with TVU CL without a specific intervention. For specific intervention (e.g., progesterone (Dodd 2006), cerclage (Alfirevic 2012; Rafael 2011); or pessary (Abdel-Aleem 2010)) based on short TVU CL, please see the relevant Cochrane Reviews.

\section{Implications for research}

Since this review found a non-significant association between knowledge of TVU CL results and a lower incidence of preterm 
birth before 34 and 37 weeks in symptomatic women, the review authors encourage further research. Future studies should look at specific populations separately (e.g., singleton versus twins; symptoms of PTL or no such symptoms), report on all pertinent maternal and perinatal outcomes, and include cost-effectiveness analyses. Most importantly, future studies should include a clear protocol for management of women based on TVU CL results, so that it can be easily evaluated and replicated.

\section{ACKNOW LEDGEMENTS}

Chris Harvey was co-author of the published protocol for this review. Jolene Seibel-Seamon helped with statistics.

As part of the pre-publication editorial process, this review has been commented on by three peers (an editor and two referees who are external to the editorial team) and the Group's Statistical Adviser.

\section{R E F E R E N C E S}

\section{References to studies included in this review}

\section{Alfirevic 2007 \{published data only\}}

Alfirevic Z, Allen-Coward H, Molina F, Vinuesa CP, Nicolaides K. Targeted therapy for threatened preterm labor based on sonographic measurement of the cervical length: a randomized controlled trial. Ultrasound in Obstetrics \& Gynecology 2007;29(1):47-50.

Carlan 1997 \{published data only\}

Carlan SJ, Richmond LB, O'Brien WF. Randomized trial of endovaginal ultrasound in preterm premature rupture of membranes. Obstetrics \& Gynecology 1997;89:458-61.

\section{Gordon 2006 \{published data only\}}

Gordon M, Robbins A, McKenna D, Howard B, Barth W. Cervical length assessment as a resource to identify twins at risk for preterm delivery (clarity study). American Journal of Obstetrics and Gynecology 2006;195(6 Suppl 1):S55.

\section{Ness 2007 \{published data only\}}

* Ness A, Visintine J, Ricci E, Berghella V. Does knowledge of cervical length and fetal fibronectin affect management of women with threatened preterm labor? A randomized trial. American Journal of Obstetrics and Gynecology 2007; 197(4):426.e1-426.e7.

Ness A, Visintine J, Ricci E, Boyle K, Berghella V. Use of fetal fibronectin and transvaginal ultrasound cervical length to triage women with suspected preterm labor: a randomized trial. American Journal of Obstetrics and Gynecology 2006;195(6 Suppl 1):S67.

Palacio 2006 \{published data only\}

Palacio M, Sanchez M, Cobo T, Figueras F, Coll O, Cararach V. Uterine cervical length to reduce length of stay in patients admitted because of preterm labor. Prospective and randomized trial. Preliminary results. Ultrasound in Obstetrics \& Gynecology 2003;22(Suppl 1):47.

* Palacio M, Sanchez M, Cobo T, Figueras F, Coll O, Cararach V, et al.Cervical length measurement to reduce length of stay in patients admitted because of preterm labor. Prospective and randomized trial. Final results. Ultrasound in Obstetrics \& Gynecology 2006;28(4):485.

\section{References to studies excluded from this review}

Beigi 2005 \{published data only\}

Beigi A, Zarrinkoub F. Elective versus ultrasound-indicated cervical cerclage in women at risk for cervical incompetence. Medical Journal of the Islamic Republic of Iran 2005;19(2):

103-7.

Burwick 2011 \{published data only\} Burwick RM, Zork NM, Lee GT, Ross MG, Kjos SL. Cervilenz assessment of cervical length compared to fetal fibronectin in the prediction of preterm delivery in women with threatened preterm labor. Journal of Maternal-Fetal \& Neonatal Medicine 2011;24(1):127-31.

Kassanos 2001 \{published data only\}

Kassanos D, Salamalekis E, Vitoratos N, Panayotopoulos $\mathrm{N}$, Loghis $\mathrm{C}$, Creatsas $\mathrm{C}$. The value of transvaginal ultrasonography in diagnosis and management of cervical incompetence. Clinical \& Experimental Obstetrics \& Gynecology 2001;28:266-8.

Lorenz 1990 \{published data only\}

Lorenz RP, Comstock CH, Bottoms SF, Marx SR. Randomized prospective trial comparing ultrasonography and pelvic examination for preterm labor surveillance. American Journal of Obstetrics and Gynecology 1990;162: 1603-10.

Matijevic 2006 \{published data only\} Matijevic R, Grgic O, Vasilj O. Is sonographic assessment of cervical length better than digital examination in screening for preterm delivery in a low-risk population?. Acta Obstetricia et Gynecologica Scandinavica 2006;85(11): 1342-7.

Owen 1999 \{published data only\}

Owen J, Neely C, Northen A. Transperineal versus endovaginal ultrasonographic examination of the cervix in the midtrimester: a blinded comparison. American Journal of Obstetrics and Gynecology 1999;181(4):780-3.

Shennan 2007 \{published data only\} Shennan A, Maternal and Fetal Research Unit (MFRU). CIRCLE study: cerclage in relation to cervical length. Maternal and Fetal Research Unit (www.mfru.org.uk/ CIRCLE.htm) (accessed 25 February 2004).

Simcox R, Bennett F, Teoh TG, Shennan AH. A randomised controlled trial of cervical scanning vs history to determine 
cerclage in high risk women (circle trial) [abstract]. Journal of Obstetrics and Gynaecology 2007;27(Suppl 1):S18. Simcox R, Seed PT, Bennett P, Teoh TG, Poston L, Shennan AH. A randomized controlled trial of cervical scanning vs history to determine cerclage in women at high risk of preterm birth (CIRCLE trial). American Journal of Obstetrics and Gynecology 2009;200(6):623.e1-6.

Van Dijken 1991 \{published data only\}

Van Dijken DKE, Wolf H, Boer K, Treffers PE. Preliminary results of a randomized trial comparing abdominal ultrasonography and digital examination. Proceedings of 13th World Congress of Gynaecology and Obstetrics (FIGO); 1991 Sept 15-20; Singapore. 1991:289.

\section{Additional references}

\section{Abdel-Aleem 2010}

Abdel-Aleem H, Shaaban OM, Abdel-Aleem MA. Cervical pessary for preventing preterm birth. Cochrane Database of Systematic Reviews 2010, Issue 9. [DOI: 10.1002/ 14651858.CD007873.pub2]

\section{Alfirevic 2012}

Alfirevic Z, Stampalija T, Roberts D, Jorgensen AL. Cervical stitch (cerclage) for preventing preterm birth in singleton pregnancy. Cochrane Database of Systematic Reviews 2012, Issue 4. [DOI: 10.1002/14651858.CD008991.pub2]

Berghella 2003

Berghella V, Bega G, Tolosa JE, Berghella M. Ultrasound assessment of the cervix. Clinical Obstetrics and Gynecology 2003;46:947-62.

Berghella 2007

Berghella V, Roman A, Daskalakis C, Ness A, Baxter JK. Gestational age at cervical length measurement and incidence of preterm birth. Obstetrics \& Gynecology 2007; 110:311-7.

\section{Deeks 2001}

Deeks JJ, Altman DG, Bradburn MJ. Statistical methods for examining heterogeneity and combining results from several studies in meta-analysis. In: Egger M, Davey Smith G, Altman DG editor(s). Systematic Reviews in Health Care: Meta-analysis in Context. London: BMJ Books, 2001.

\section{Dodd 2006}

Dodd JM, Flenday V, Cincotta R, Crowther CA. Prenatal administration of progesterone for preventing preterm birth in women considered to be at risk of preterm birth. Cochrane Database of Systematic Reviews 2006, Issue 1. [DOI: 10.1002/14651858.CD004947.pub2]

\section{Egger 1997}

Egger M, Smith GD, Schneider M, Minder C. Bias in meta-analysis detected by a simple, graphical test. $B M J$ 1997;315:629-34.

\section{Gates 2005}

Gates S. Methodological Guidelines. In: the Editorial Team. Pregnancy and Childbirth Group. About The Cochrane Collaboration (Collaborative Review Groups (CRGs)) 2005, Issue 2.

\section{Grimes-Dennis 2007}

Grimes-Dennis J, Berghella V. Cervical length and prediction of preterm birth. Current Opinion in Obstetrics and Gynecology 2007;19:191-5.

\section{Harbord 2006}

Harbord RM, Egger M, Sterne JA. A modified test for small-study effects in meta-analyses of controlled trials with binary endpoints. Statistics in Medicine 2006;25:3443-57.

\section{Hernandez-Andrade 2012}

Hernandez-Andrade E, Romero R, Ahn H, Hussein Y, Yeo L, Korzeniewski SJ, et al.Transabdominal evaluation of uterine cervical length during pregnancy fails to identify a substantial number of women with a short cervix. Journal of Maternal-Fetal and Neonatal Medicine 2012;25(9):1682-9.

\section{Higgins 2008}

Higgins JPT, Green S, editors. Cochrane Handbook for Systematic Reviews of Interventions Version 5.0.0 [updated February 2008]. The Cochrane Collaboration, 2008. Available from www.cochrane-handbook.org.

\section{Higgins 2011}

Higgins JPT, Green S, editors. Cochrane Handbook for Systematic Reviews of Interventions Version 5.1.0 [updated March 2011]. The Cochrane Collaboration, 2011. Available from www.cochrane-handbook.org.

\section{National Vital Statistics Report 2011}

Martin JA, Hamilton BE, Ventura SJ, Osterman MJK, Kirmeyer S, et al.Births: final data for 2009. National Vital Statistics Report 2011;60(1):1-72.

\section{Rafael 2011}

Rafael TJ, Berghella V, Alfirevic Z. Cervical stitch (cerclage) for preventing preterm birth in multiple pregnancy. Cochrane Database of Systematic Reviews 2011, Issue 6. [DOI: 10.1002/14651858.CD009166]

\section{RevMan 2008}

The Cochrane Collaboration. Review Manager (RevMan). 5.0. Copenhagen, The Nordic Cochrane Centre: The Cochrane Collaboration, 2008.

\section{RevMan 2011}

The Nordic Cochrane Centre, The Cochrane Collaboration. Review Manager (RevMan). 5.1. Copenhagen: The Nordic Cochrane Centre, The Cochrane Collaboration, 2011.

\section{References to other published versions of this review}

\section{Berghella 2008}

Berghella V, Baxter J, Harvey C, Hendrix NW. Cervical assessment by ultrasound for preventing preterm delivery. Cochrane Database of Systematic Reviews 2008, Issue 3. [DOI: 10.1002/14651858.CD007235]

\section{Berghella 2009}

Berghella V, Baxter JK, Hendrix NW. Cervical assessment by ultrasound for preventing preterm delivery. Cochrane Database of Systematic Reviews 2009, Issue 3. [DOI: 10.1002/14651858.CD007235.pub2]

* Indicates the major publication for the study 


\section{CHARACTERISTICS OF STUDIES}

\section{Characteristics of included studies [ordered by study ID]}

Alfirevic 2007

\begin{tabular}{ll}
\hline Methods & RCT. \\
\hline Participants & $\begin{array}{l}\text { Singleton gestations; uterine contractions at }<34 \text { weeks; and clinical decision to use } \\
\text { steroids and tocolytics. } \mathrm{N}=41\end{array}$ \\
\hline Interventions & $\begin{array}{l}\text { TVU CL knowledge or not (the control group did not receive TVU CL) } \\
\text { Time TVU CL results available: not specified. } \\
\text { Protocol for TVU knowledge group: yes. }\end{array}$ \\
\hline Outcomes & Primary: incidence of women still pregnant at 7 days. \\
\hline Notes & $\begin{array}{l}\text { Intention-to-treat; only singletons; protocol for management of TVU CL group } \\
\text { Short TVU CL }(<15 \text { mm): } 7 / 21 \text { (33\%) in knowledge group; not done in other group }\end{array}$ \\
\hline
\end{tabular}

Risk of bias

\begin{tabular}{|c|c|c|}
\hline Bias & Authors' judgement & Support for judgement \\
\hline $\begin{array}{l}\text { Random sequence generation (selection } \\
\text { bias) }\end{array}$ & Low risk & Computer-generated randomization. \\
\hline Allocation concealment (selection bias) & Low risk & Consecutively numbered sealed envelopes. \\
\hline $\begin{array}{l}\text { Blinding of participants and personnel } \\
\text { (performance bias) } \\
\text { All outcomes }\end{array}$ & High risk & $\begin{array}{l}\text { Women and physicians knew which group was randomized to } \\
\text { 'knowledge' or 'no knowledge' }\end{array}$ \\
\hline $\begin{array}{l}\text { Blinding of outcome assessment (detection } \\
\text { bias) } \\
\text { All outcomes }\end{array}$ & Low risk & $\begin{array}{l}\text { Some blinding attempted - "Women allocated to the experimen- } \\
\text { tal group had a transvaginal scan to measure the cervical length, } \\
\text { which was performed by a member of the research team who } \\
\text { was not involved in the care of the patient" - but the control } \\
\text { group did not have a transvaginal scan } \\
\text { Primary outcome - is an objective outcome (delivery within } 7 \\
\text { days) }\end{array}$ \\
\hline $\begin{array}{l}\text { Incomplete outcome data (attrition bias) } \\
\text { All outcomes }\end{array}$ & Low risk & No incomplete outcomes. Intention-to-treat analysis. \\
\hline Selective reporting (reporting bias) & Low risk & $\begin{array}{l}\text { Primary outcome was delivery within } 7 \text { days. All other outcomes } \\
\text { reported }\end{array}$ \\
\hline Other bias & Low risk & Baseline characteristics similar. \\
\hline
\end{tabular}




\begin{tabular}{|c|c|c|}
\hline Methods & \multicolumn{2}{|l|}{ RCT. } \\
\hline Participants & \multicolumn{2}{|c|}{ Singleton gestations; PPROM; 24 to 34 weeks. $\mathrm{N}=92}$. \\
\hline Interventions & \multicolumn{2}{|c|}{$\begin{array}{l}\text { TVU CL or not (the control group did not receive TVU CL). } \\
\text { Time TVU CL results available: not specified. } \\
\text { Protocol for TVU knowledge group: no. }\end{array}$} \\
\hline Outcomes & \multicolumn{2}{|c|}{ Primary: maternal infection. } \\
\hline Notes & \multicolumn{2}{|c|}{$\begin{array}{l}\text { Intention-to-treat; only singletons; PPROM; no protocol (really a safety study for TVU } \\
\text { CL in PPROM women) } \\
\text { Short TVU CL ( }<25 \mathrm{~mm}): 14 / 45(31 \%) \text { in knowledge group; not done in other group }\end{array}$} \\
\hline \multicolumn{3}{|l|}{ Risk of bias } \\
\hline Bias & Authors' judgement & Support for judgement \\
\hline $\begin{array}{l}\text { Random sequence generation (selection } \\
\text { bias) }\end{array}$ & Low risk & "Randomly-generated assignment." \\
\hline Allocation concealment (selection bias) & Low risk & "Randomly-generated" assignments in sealed envelopes. \\
\hline $\begin{array}{l}\text { Blinding of participants and personnel } \\
\text { (performance bias) } \\
\text { All outcomes }\end{array}$ & High risk & Study group had weekly US while controls had none. \\
\hline $\begin{array}{l}\text { Blinding of outcome assessment (detection } \\
\text { bias) } \\
\text { All outcomes }\end{array}$ & Unclear risk & Not reported. \\
\hline $\begin{array}{l}\text { Incomplete outcome data (attrition bias) } \\
\text { All outcomes }\end{array}$ & Low risk & $1 \%$ explained. \\
\hline Selective reporting (reporting bias) & Low risk & $\begin{array}{l}\text { Primary outcome was chorioamnionitis. All other outcomes re- } \\
\text { ported }\end{array}$ \\
\hline Other bias & Unclear risk & No baseline characteristics table. \\
\hline
\end{tabular}

\section{Gordon 2006}

\begin{tabular}{ll}
\hline Methods & RCT. \\
\hline Participants & Twin gestations; asymptomatic and with PTL symptoms; 15 to 34 weeks. N = 125 \\
\hline Interventions & $\begin{array}{l}\text { TVU CL screening at } 15 \text { to } 28 \text { weeks, and if PTL symptoms develop or not (the control } \\
\text { group did not receive TVU CL) } \\
\text { Time TVU CL results available: not specified. } \\
\text { Protocol for TVU knowledge group: yes. }\end{array}$ \\
\hline $\begin{array}{l}\text { Cervical assessment by ultrasound for preventing preterm delivery (Review) } \\
\text { Copyright } \odot \mathbf{2 0 1 3} \text { The Cochrane Collaboration. Published by John Wiley \& Sons, Ltd. }\end{array}$
\end{tabular}




\section{Gordon 2006 (Continued)}

\begin{tabular}{|c|c|c|}
\hline Outcomes & \multicolumn{2}{|c|}{ Primary: length of gestation. } \\
\hline Notes & \multicolumn{2}{|c|}{$\begin{array}{l}\text { Only abstract published; unclear if intention-to-treat; only twins; protocol for manage- } \\
\text { ment of TVU CL group } \\
\text { Short TVU CL not available. }\end{array}$} \\
\hline \multicolumn{3}{|l|}{ Risk of bias } \\
\hline Bias & Authors' judgement & Support for judgement \\
\hline $\begin{array}{l}\text { Random sequence generation (selection } \\
\text { bias) }\end{array}$ & Unclear risk & Randomization not described. \\
\hline Allocation concealment (selection bias) & Unclear risk & Not described. \\
\hline $\begin{array}{l}\text { Blinding of participants and personnel } \\
\text { (performance bias) } \\
\text { All outcomes }\end{array}$ & High risk & Different protocols for study and control groups. \\
\hline $\begin{array}{l}\text { Blinding of outcome assessment (detection } \\
\text { bias) } \\
\text { All outcomes }\end{array}$ & Low risk & Primary outcome objective - length of gestation. \\
\hline $\begin{array}{l}\text { Incomplete outcome data (attrition bias) } \\
\text { All outcomes }\end{array}$ & Unclear risk & No incomplete outcomes mentioned. \\
\hline Selective reporting (reporting bias) & Unclear risk & Primary outcome was gestational age at delivery. \\
\hline Other bias & Unclear risk & Abstract only, so data reported are limited. \\
\hline
\end{tabular}

Ness 2007

\begin{tabular}{|c|c|}
\hline Methods & RCT. \\
\hline Participants & $\begin{array}{l}\text { Singleton (and } 3 \text { twin) gestations; uterine contractions or symptoms suggestive of PTL } \\
\text { at } 24 \text { to } 336 / 7 \text { weeks. } N=100\end{array}$ \\
\hline Interventions & $\begin{array}{l}\text { TVU CL knowledge or not (the control group did receive TVU CL, but results were } \\
\text { blinded to managing physicians) } \\
\text { Time TVU CL results available: not specified. } \\
\text { Protocol for TVU knowledge group: yes. }\end{array}$ \\
\hline Outcomes & Primary: time from initial evaluation to discharge. \\
\hline Notes & $\begin{array}{l}\text { Intention to treat; } 97 \% \text { singletons; protocol for management of TVU CL group, which } \\
\text { included management based on FFN for women with CL } 20 \text { to } 29 \mathrm{~mm} \\
\text { Short TVU CL }(<20 \mathrm{~mm}): 11 / 51(22 \%) \text { in knowledge group; } 7 / 49(15 \%) \text { in the control } \\
\text { group }\end{array}$ \\
\hline
\end{tabular}




\section{Ness 2007 (Continued)}

\section{Risk of bias}

\begin{tabular}{l|l|l}
\hline Bias & Authors' judgement & Support for judgement \\
\hline $\begin{array}{l}\text { Random sequence generation (selection } \\
\text { bias) }\end{array}$ & Low risk & Computer-generated random numbers. \\
\hline $\begin{array}{l}\text { Allocation concealment (selection bias) } \\
\text { Blinding of participants and personnel } \\
\text { (performance bias) }\end{array}$ & Low risk risk & Numbered, sealed opaque envelopes. \\
\hline $\begin{array}{l}\text { All outcomes } \\
\text { Blinding of outcome assessment (detection } \\
\text { bias) } \\
\text { All outcomes }\end{array}$ & Unclear risk & $\begin{array}{l}\text { Women and physicians knew which group was randomized to } \\
\text { 'knowledge' or 'no knowledge' }\end{array}$ \\
\hline $\begin{array}{l}\text { Incomplete outcome data (attrition bias) } \\
\text { All outcomes }\end{array}$ & Low risk & Not reported. \\
\hline $\begin{array}{l}\text { Selective reporting (reporting bias) } \\
\text { Other bias }\end{array}$ & Low risk & Intention-to-treat analyses. \\
\hline & Low risk & $\begin{array}{l}\text { Primary outcome time from evaluation to discharge. All other } \\
\text { outcomes reported }\end{array}$ \\
\hline
\end{tabular}

Palacio 2006

\begin{tabular}{l|l}
\hline Methods & RCT. \\
\hline Participants & Singleton gestations; PTL at 24 to $356 / 7$ weeks. N = 149. \\
\hline Interventions & $\begin{array}{l}\text { TVU CL knowledge or not (the control group did receive TVU CL, but results were } \\
\text { blinded to managing physicians) } \\
\text { Time TVU CL results available: not specified. } \\
\text { Protocol for TVU knowledge group: yes. }\end{array}$ \\
\hline Outcomes & \begin{tabular}{l} 
Primary: hospital length of stay. \\
\hline Notes
\end{tabular} \\
$\begin{array}{l}\text { Only abstract published; } 7 \text { women lost to follow up; only singletons; protocol for man- } \\
\text { agement of TVU CL group } \\
\text { Short TVU CL }(<25 \text { mm): } 22 / 75 \text { (29\%) in knowledge group; } 20 / 74(27 \%) \text { in the } \\
\text { control group }\end{array}$ \\
\hline
\end{tabular}

\section{Risk of bias}

Bias

\section{Authors' judgement Support for judgement}


Palacio 2006 (Continued)

\begin{tabular}{l|l|l}
\hline $\begin{array}{l}\text { Random sequence generation (selection } \\
\text { bias) }\end{array}$ & Unclear risk & Randomization not described. \\
\hline $\begin{array}{l}\text { Allocation concealment (selection bias) } \\
\begin{array}{l}\text { Blinding of participants and personnel } \\
\text { (performance bias) } \\
\text { All outcomes }\end{array}\end{array}$ & Unclear risk & Not described. \\
\hline $\begin{array}{l}\text { Blinding of outcome assessment (detection } \\
\text { bias) } \\
\text { All outcomes }\end{array}$ & Unclear risk & $\begin{array}{l}\text { Women and physicians knew which group was randomized to } \\
\text { knowledge' or 'no knowledge' }\end{array}$ \\
\hline $\begin{array}{l}\text { Incomplete outcome data (attrition bias) } \\
\text { All outcomes }\end{array}$ & High risk & Not reported. \\
\hline \begin{tabular}{l} 
Selective reporting (reporting bias) \\
\hline $\begin{array}{l}\text { Other bias }\end{array}$
\end{tabular} & Unclear risk & Length of hospital stay primary outcome. \\
\hline
\end{tabular}

CL: cervical length

FFN: fetal fibronectin

PPROM: preterm premature rupture of membranes

PTL: preterm labor

RCT: randomized controlled trial

TVU: transvaginal ultrasound

US: ultrasound

Characteristics of excluded studies [ordered by study ID]

\begin{tabular}{l|l}
\hline Study & Reason for exclusion \\
\hline Beigi 2005 & Compared history-indicated to ultrasound-indicated cerclage. \\
\hline Burwick 2011 & $\begin{array}{l}\text { Used Cervilenz, which is a plastic instrument to measure the vaginal part of the cervix. This is outside the scope } \\
\text { of our review, which focuses on CL measured exclusively by TVU }\end{array}$ \\
\hline Kassanos 2001 & Compared history-indicated to ultrasound-indicated cerclage. \\
\hline Lorenz 1990 & $\begin{array}{l}\text { Control group was not 'no ultrasound' or 'no knowledge', but was manual digital cervical exam. Interestingly, } \\
\text { the study group utilized transabdominal ultrasound }\end{array}$ \\
\hline Matijevic 2006 & \begin{tabular}{l} 
The TVU CL information was blinded and not used for management \\
\hline
\end{tabular}
\end{tabular}


(Continued)

Owen 1999 TVU information was not used for clinical care and no data on outcomes were provided

Shennan 2007 Compared history-indicated to ultrasound-indicated cerclage.

Van Dijken 1991 Control group was not 'no ultrasound' or 'no knowledge', but was manual digital cervical exam. Interestingly, the study group utilized transabdominal - not TVU

CL: cervical length

TVU: transvaginal ultrasound 
DATA AND ANALYSES

Comparison 1. TVU CL knowledge versus no knowledge (asymptomatic twins without PTL or PPROM)

\begin{tabular}{lccll} 
Outcome or subgroup title & $\begin{array}{c}\text { No. of } \\
\text { studies }\end{array}$ & $\begin{array}{c}\text { No. of } \\
\text { participants }\end{array}$ & \multicolumn{1}{c}{ Statistical method } & Effect size \\
\hline 1 Preterm birth <36 weeks & 1 & 125 & Risk Ratio (M-H, Fixed, 95\% CI) & $1.27[0.85,1.90]$ \\
2 Preterm birth <34 weeks & 1 & 125 & Risk Ratio (M-H, Fixed, 95\% CI) & $0.62[0.30,1.25]$ \\
3 Preterm birth <32 weeks & 1 & 125 & Risk Ratio (M-H, Fixed, 95\% CI) & $0.56[0.17,1.83]$ \\
4 Preterm birth <30 weeks & 1 & 125 & Risk Ratio (M-H, Fixed, 95\% CI) & $0.20[0.02,1.64]$ \\
5 Gestational age at delivery & 1 & 125 & Mean Difference (IV, Fixed, 95\% CI) & $0.20[-0.74,1.14]$ \\
6 Birthweight & 1 & 125 & Mean Difference (IV, Fixed, 95\% CI) & $155.0[-57.61,367$. \\
& & & & \\
7 Maternal hospitalization (PTL) & 1 & 125 & Risk Ratio (M-H, Fixed, 95\% CI) & $1.29[0.75,2.23]$ \\
8 Tocolysis & 1 & 125 & Risk Ratio (M-H, Fixed, 95\% CI) & $1.34[0.74,2.42]$ \\
9 Steroids for fetal lung maturity & 1 & 125 & Risk Ratio (M-H, Fixed, 95\% CI) & $0.79[0.49,1.26]$ \\
\hline
\end{tabular}

Comparison 2. TVU CL knowledge versus no knowledge (symptomatic singletons with PTL)

\begin{tabular}{lccll} 
Outcome or subgroup title & $\begin{array}{c}\text { No. of } \\
\text { studies }\end{array}$ & $\begin{array}{c}\text { No. of } \\
\text { participants }\end{array}$ & \multicolumn{1}{c}{ Statistical method } & Effect size \\
\hline 1 Preterm birth < 37 weeks & 2 & 242 & Risk Ratio (M-H, Random, 95\% CI) & $0.59[0.26,1.32]$ \\
2 Preterm birth < 34 weeks & 3 & 256 & Risk Ratio (M-H, Fixed, 95\% CI) & $0.55[0.25,1.20]$ \\
3 Preterm birth < 28 weeks & 2 & 137 & Risk Ratio (M-H, Fixed, 95\% CI) & $0.0[0.0,0.0]$ \\
4 gestational age at delivery & 3 & 290 & Mean Difference (IV, Fixed, 95\% CI) & $0.64[0.03,1.25]$ \\
5 Birthweight < 2500 grams & 1 & 70 & Risk Ratio (M-H, Fixed, 95\% CI) & $0.71[0.21,2.44]$ \\
6 Perinatal death & 1 & 97 & Risk Ratio (M-H, Fixed, 95\% CI) & $0.0[0.0,0.0]$ \\
7 Maternal hospitalization & 1 & 93 & Risk Ratio (M-H, Fixed, 95\% CI) & $2.94[0.85,10.16]$ \\
8 Tocolysis & 2 & 102 & Risk Ratio (M-H, Random, 95\% CI) & $0.85[0.11,6.58]$ \\
9 Steroids for fetal lung maturity & 2 & 114 & Risk Ratio (M-H, Random, 95\% CI) & $1.72[0.15,19.64]$ \\
\hline
\end{tabular}

Comparison 3. TVU CL knowledge versus no knowledge (symptomatic singletons with PPROM)

\begin{tabular}{lcccc} 
Outcome or subgroup title & $\begin{array}{c}\text { No. of } \\
\text { studies }\end{array}$ & $\begin{array}{c}\text { No. of } \\
\text { participants }\end{array}$ & Statistical method & Effect size \\
\hline 1 Birthweight < 2500 grams & 1 & 92 & Mean Difference (IV, Fixed, 95\% CI) & $31.0[-162.16,224$. \\
& 1 & 92 & Risk Ratio (M-H, Fixed, 95\% CI) & $16]$ \\
2 Chorioamnionitis & 1 & 92 & Risk Ratio (M-H, Fixed, 95\% CI) & $0.72[0.34,1.52]$ \\
3 Endometritis & 1 & 92 & Risk Ratio (M-H, Fixed, 95\% CI) & $1.39[0.33,5.88]$ \\
4 Neonatal infection & & & &
\end{tabular}


Analysis I.I. Comparison I TVU CL knowledge versus no knowledge (asymptomatic twins without PTL or PPROM), Outcome I Preterm birth $<36$ weeks.

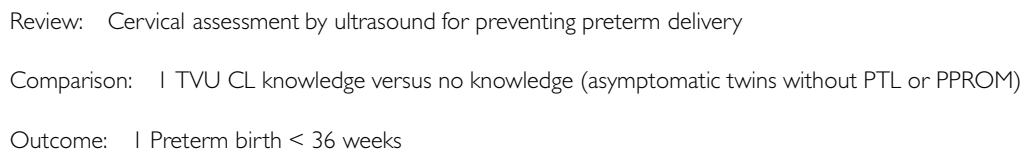

\begin{tabular}{|c|c|c|c|c|c|}
\hline Study or subgroup & $\begin{array}{r}\text { Experimental } \\
n / N\end{array}$ & $\begin{array}{r}\text { Control } \\
n / N\end{array}$ & $\begin{array}{c}\text { Risk Ratio } \\
\text { M-H,Fixed,95\% Cl }\end{array}$ & Weight & $\begin{array}{r}\text { Risk Ratio } \\
\text { M-H,Fixed,95\% Cl }\end{array}$ \\
\hline Gordon 2006 & $31 / 63$ & $24 / 62$ & & $100.0 \%$ & $1.27[0.85,1.90]$ \\
\hline Total (95\% CI) & 63 & 62 & - & $100.0 \%$ & $1.27[0.85,1.90]$ \\
\hline \multicolumn{6}{|c|}{ Total events: 31 (Experimental), 24 (Control) } \\
\hline \multicolumn{6}{|c|}{ Heterogeneity: not applicable } \\
\hline \multicolumn{6}{|c|}{ Test for overall effect: $Z=1.17(P=0.24)$} \\
\hline Test for subgroup diff & Not applicable & & & & \\
\hline
\end{tabular}

Analysis I.2. Comparison I TVU CL knowledge versus no knowledge (asymptomatic twins without PTL or PPROM), Outcome 2 Preterm birth < 34 weeks.

Review: Cervical assessment by ultrasound for preventing preterm delivery

Comparison: I TVU CL knowledge versus no knowledge (asymptomatic twins without PTL or PPROM)

Outcome: 2 Preterm birth $<34$ weeks

\begin{tabular}{|c|c|c|c|c|c|}
\hline \multirow[t]{2}{*}{ Study or subgroup } & Experimental & Control & Risk Ratio & Weight & Risk Ratio \\
\hline & $\mathrm{n} / \mathrm{N}$ & $\mathrm{n} / \mathrm{N}$ & M-H,Fixed,95\% Cl & & M-H,Fixed,95\% Cl \\
\hline Gordon 2006 & $10 / 63$ & $16 / 62$ & & $100.0 \%$ & $0.62[0.30,1.25]$ \\
\hline Total $(95 \%$ CI $)$ & 63 & 62 & & $100.0 \%$ & $0.62[0.30,1.25]$ \\
\hline
\end{tabular}

Total events: 10 (Experimental), 16 (Control)

Heterogeneity: not applicable

Test for overall effect: $Z=1.35(P=0.18)$

Test for subgroup differences: Not applicable 
Analysis I.3. Comparison I TVU CL knowledge versus no knowledge (asymptomatic twins without PTL or PPROM), Outcome 3 Preterm birth $<32$ weeks.

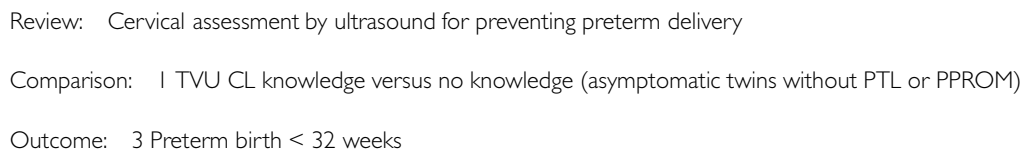

\begin{tabular}{|c|c|c|c|c|c|}
\hline \multirow[t]{2}{*}{ Study or subgroup } & Experimental & Control & Risk Ratio & \multirow[t]{2}{*}{ Weight } & Risk Ratio \\
\hline & $\mathrm{n} / \mathrm{N}$ & $\mathrm{n} / \mathrm{N}$ & M-H,Fixed,95\% Cl & & M-H,Fixed,95\% Cl \\
\hline Gordon 2006 & $4 / 63$ & $7 / 62$ & & $100.0 \%$ & $0.56[0.17,1.83]$ \\
\hline Total (95\% CI) & 63 & 62 & & $100.0 \%$ & $0.56[0.17,1.83]$ \\
\hline \multicolumn{6}{|c|}{ Total events: 4 (Experimental), 7 (Control) } \\
\hline \multicolumn{6}{|c|}{ Heterogeneity: not applicable } \\
\hline \multicolumn{6}{|c|}{ Test for overall effect: $Z=0.96(P=0.34)$} \\
\hline Test for subgroup diff & Not applicable & & & & \\
\hline
\end{tabular}

Analysis I.4. Comparison I TVU CL knowledge versus no knowledge (asymptomatic twins without PTL or PPROM), Outcome 4 Preterm birth $<30$ weeks.

Review: Cervical assessment by ultrasound for preventing preterm delivery

Comparison: I TVU CL knowledge versus no knowledge (asymptomatic twins without PTL or PPROM)

Outcome: 4 Preterm birth $<30$ weeks

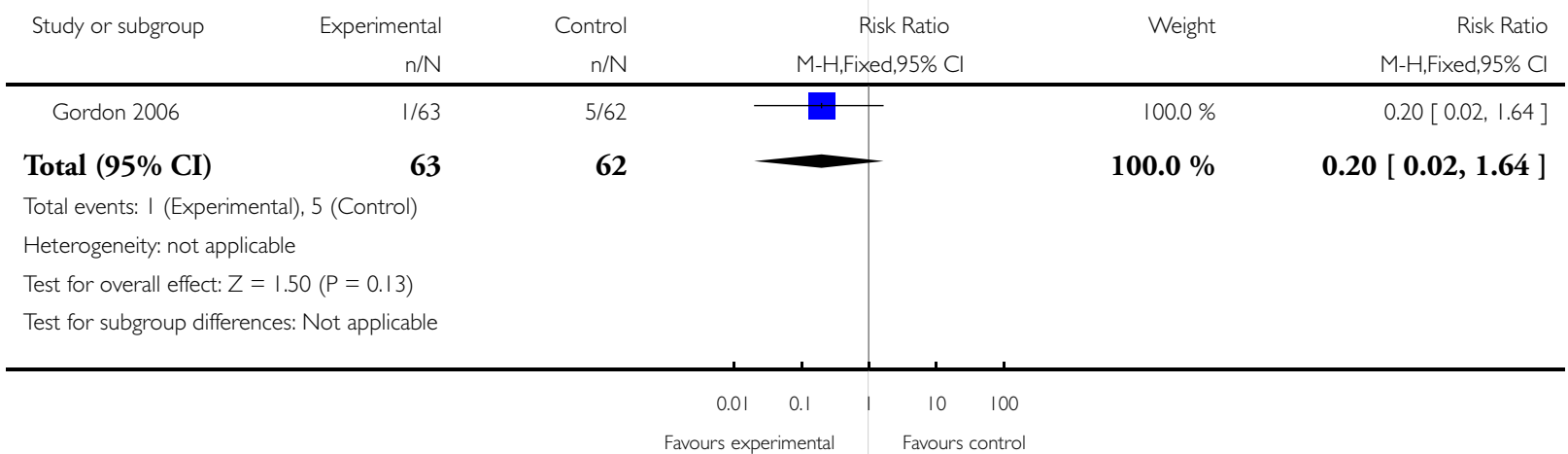


Analysis I.5. Comparison I TVU CL knowledge versus no knowledge (asymptomatic twins without PTL or PPROM), Outcome 5 Gestational age at delivery.

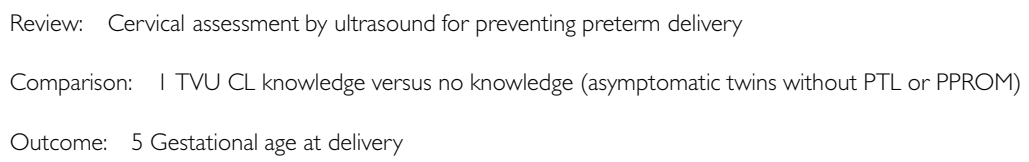

\begin{tabular}{|c|c|c|c|c|c|c|c|}
\hline \multirow[t]{2}{*}{ Study or subgroup } & \multirow{2}{*}{$\begin{array}{r}\text { Experimental } \\
N\end{array}$} & \multicolumn{3}{|c|}{ Control } & \multirow{2}{*}{$\begin{array}{c}\text { Mean } \\
\text { Difference } \\
\text { IV,Fixed,95\% Cl }\end{array}$} & \multirow[t]{2}{*}{ Weight } & \multirow{2}{*}{$\begin{array}{r}\text { Mean } \\
\text { Difference } \\
\text { IV,Fixed,95\% Cl}\end{array}$} \\
\hline & & Mean(SD) & N & Mean(SD) & & & \\
\hline Gordon 2006 & 63 & $35.7(2.2)$ & 62 & $35.5(3.1)$ & & $100.0 \%$ & $0.20[-0.74,1.14]$ \\
\hline Total (95\% CI) & 63 & & 62 & & $\bullet$ & $100.0 \%$ & $0.20[-0.74,1.14]$ \\
\hline \multicolumn{8}{|c|}{ Heterogeneity: not applicable } \\
\hline \multicolumn{8}{|c|}{ Test for overall effect: $Z=0.42(P=0.68)$} \\
\hline \multicolumn{8}{|c|}{ Test for subgroup differences: Not applicable } \\
\hline
\end{tabular}

Analysis I.6. Comparison I TVU CL knowledge versus no knowledge (asymptomatic twins without PTL or PPROM), Outcome 6 Birthweight.

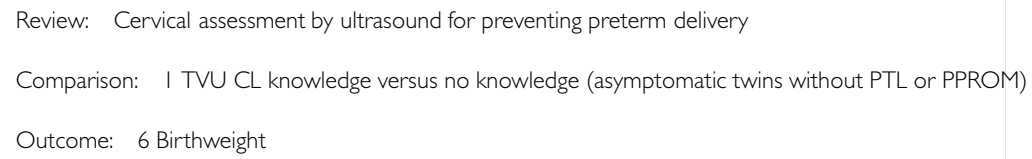

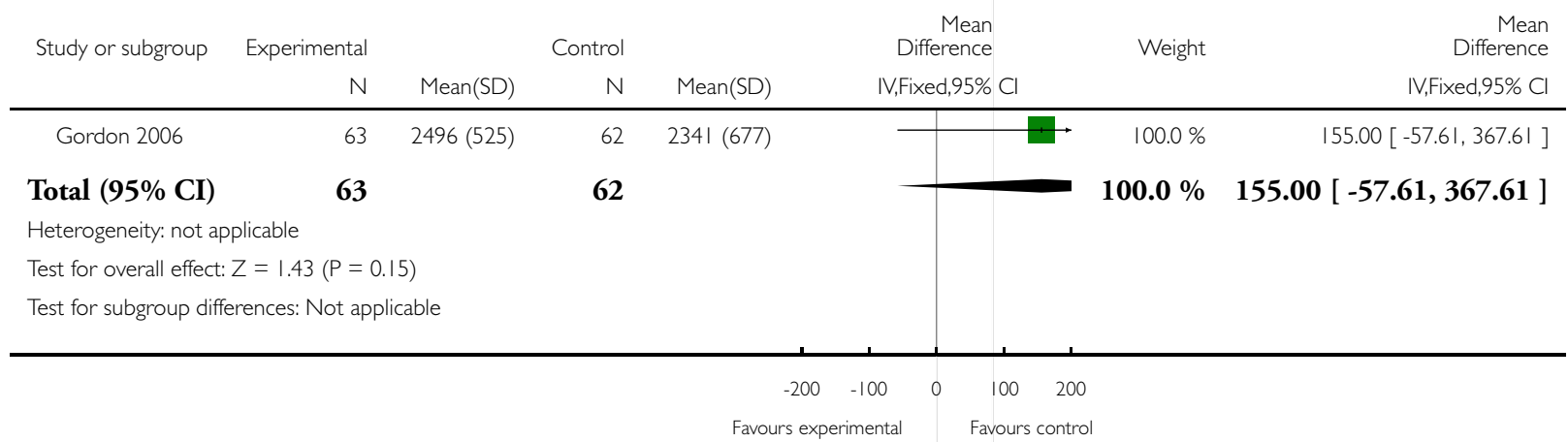


Analysis I.7. Comparison I TVU CL knowledge versus no knowledge (asymptomatic twins without PTL or PPROM), Outcome 7 Maternal hospitalization (PTL).

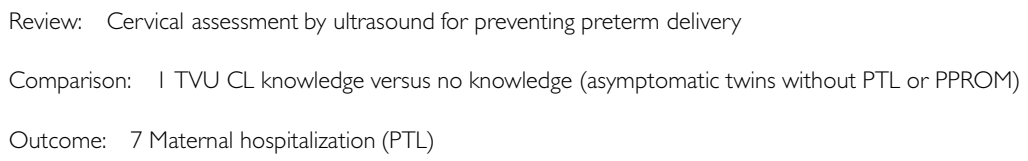

Total events: 21 (Experimental), 16 (Control)

Heterogeneity: not applicable

Test for overall effect: $Z=0.92(P=0.36)$

Test for subgroup differences: Not applicable

$\begin{array}{ccccc}0.01 & 0.1 & 1 & 10 & 100 \\ \text { Favours experimental } & & \text { Favours control }\end{array}$

\section{Analysis I.8. Comparison I TVU CL knowledge versus no knowledge (asymptomatic twins without PTL or} PPROM), Outcome 8 Tocolysis.

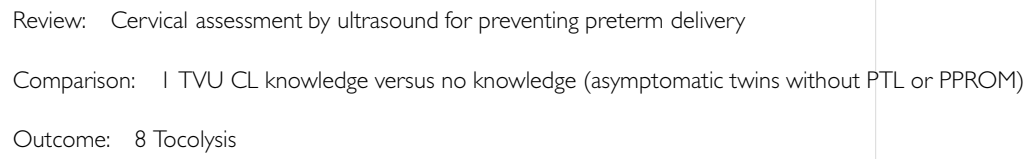

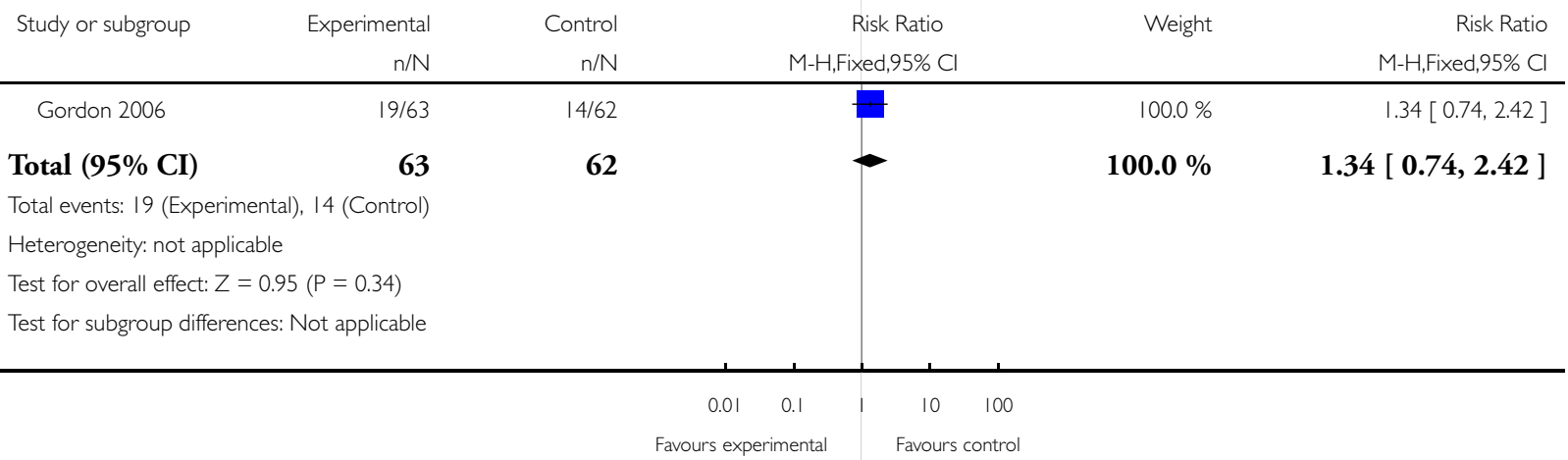


Analysis 1.9. Comparison I TVU CL knowledge versus no knowledge (asymptomatic twins without PTL or PPROM), Outcome 9 Steroids for fetal lung maturity.

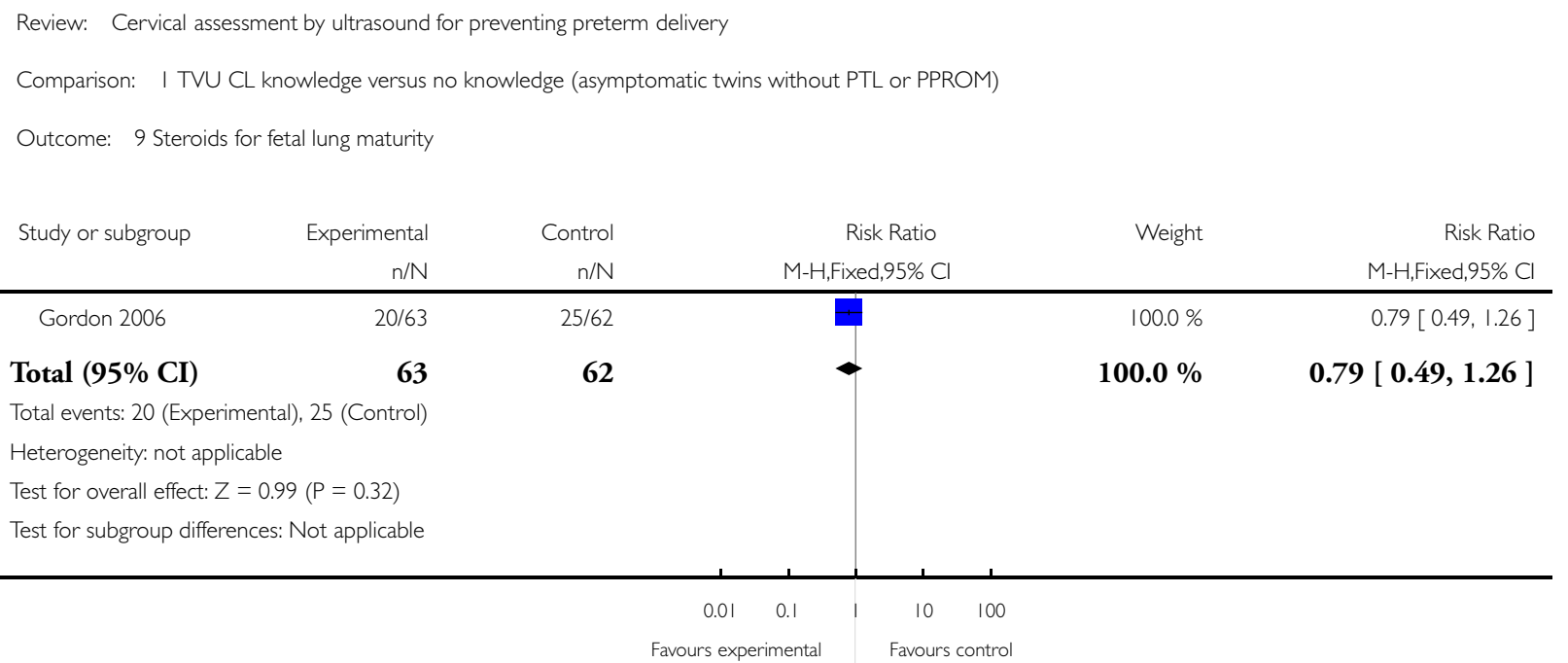

Analysis 2.I. Comparison 2 TVU CL knowledge versus no knowledge (symptomatic singletons with PTL), Outcome I Preterm birth $<37$ weeks.

Review: Cervical assessment by ultrasound for preventing preterm delivery

Comparison: 2 TVU CL knowledge versus no knowledge (symptomatic singletons with PTL)

Outcome: I Preterm birth $<37$ weeks

Study or subgroup NVU CL knowledge No TVU CL

\begin{tabular}{|c|c|c|c|c|c|}
\hline Study or subgroup & IVU CL knowledge & $\begin{array}{r}\text { Wledge } \\
\text { n/N }\end{array}$ & $\begin{array}{c}\text { Risk Ratıo } \\
\text { M- } \\
\text { H,Random,95\% } \\
\text { Cl }\end{array}$ & Weight & $\begin{array}{c}\text { Risk Ratio } \\
\text { M- } \\
\text { H,Random,95\% } \\
\text { Cl }\end{array}$ \\
\hline Ness 2007 & $6 / 46$ & $17 / 47$ & 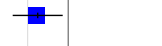 & $41.4 \%$ & $0.36[0.16,0.83]$ \\
\hline Palacio 2006 & $21 / 75$ & $25 / 74$ & & $58.6 \%$ & $0.83[0.51,1.34]$ \\
\hline
\end{tabular}

Total $(95 \% \mathrm{CI})$

$121 \quad 121$

12

$100.0 \%$

$0.59[0.26,1.32$ ]

Total events: 27 (TVU CL knowledge), 42 (No TVU CL knowledge)

Heterogeneity: $\mathrm{Tau}^{2}=0.23 ; \mathrm{Chi}^{2}=2.90, \mathrm{df}=\mathrm{I}(\mathrm{P}=0.09) ; \mathrm{I}^{2}=66 \%$

Test for overall effect: $Z=1.29(P=0.20)$

Test for subgroup differences: Not applicable

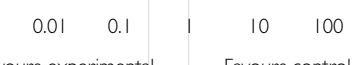

Cervical assessment by ultrasound for preventing preterm delivery (Review)

Copyright $\odot 2013$ The Cochrane Collaboration. Published by John Wiley \& Sons, Ltd. 
Analysis 2.2. Comparison 2 TVU CL knowledge versus no knowledge (symptomatic singletons with PTL), Outcome 2 Preterm birth $<34$ weeks.

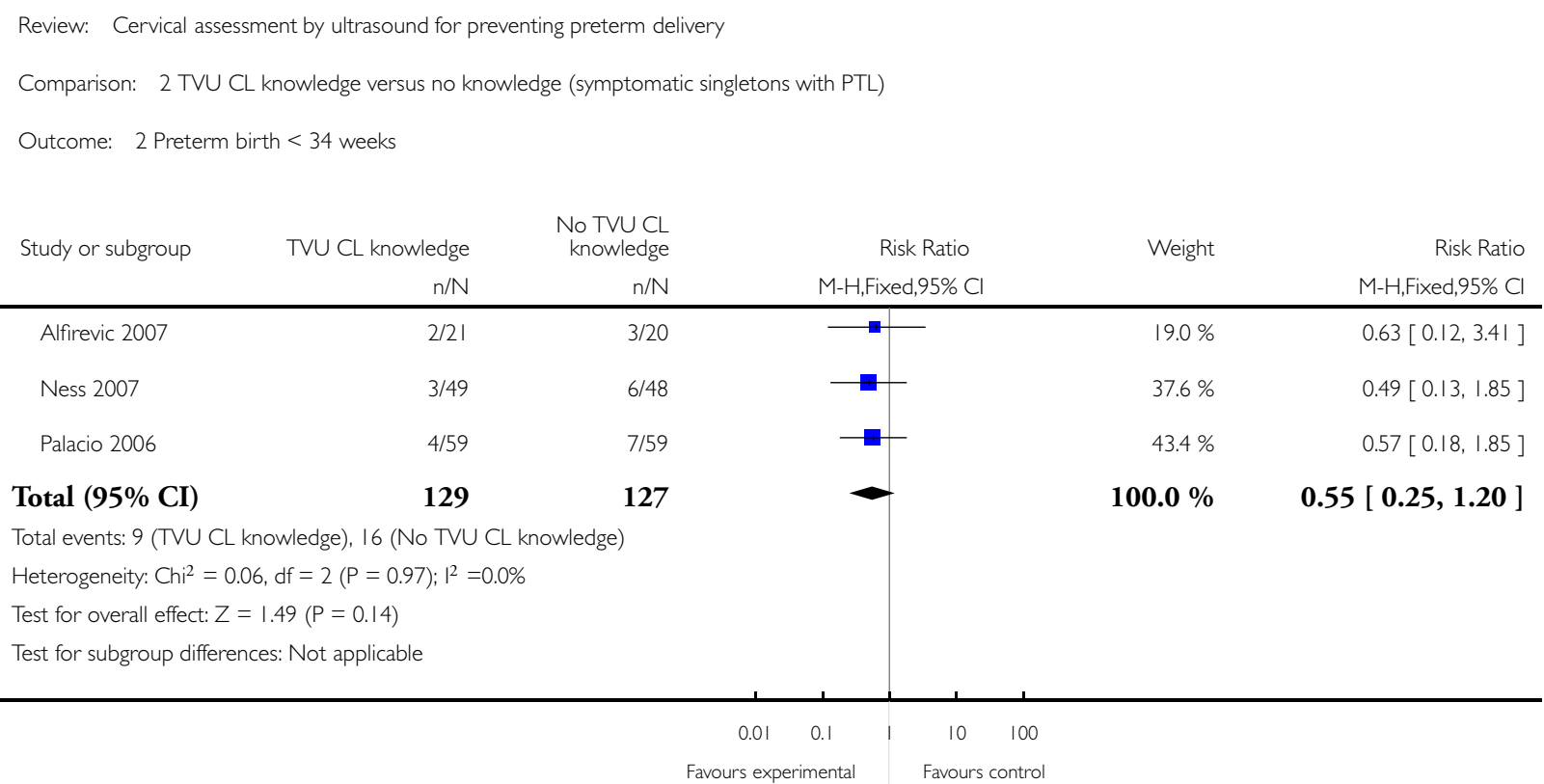


Analysis 2.3. Comparison 2 TVU CL knowledge versus no knowledge (symptomatic singletons with PTL), Outcome 3 Preterm birth $<28$ weeks.

Review: Cervical assessment by ultrasound for preventing preterm delivery

Comparison: 2 TVU CL knowledge versus no knowledge (symptomatic singletons with PTL)

Outcome: 3 Preterm birth $<28$ weeks

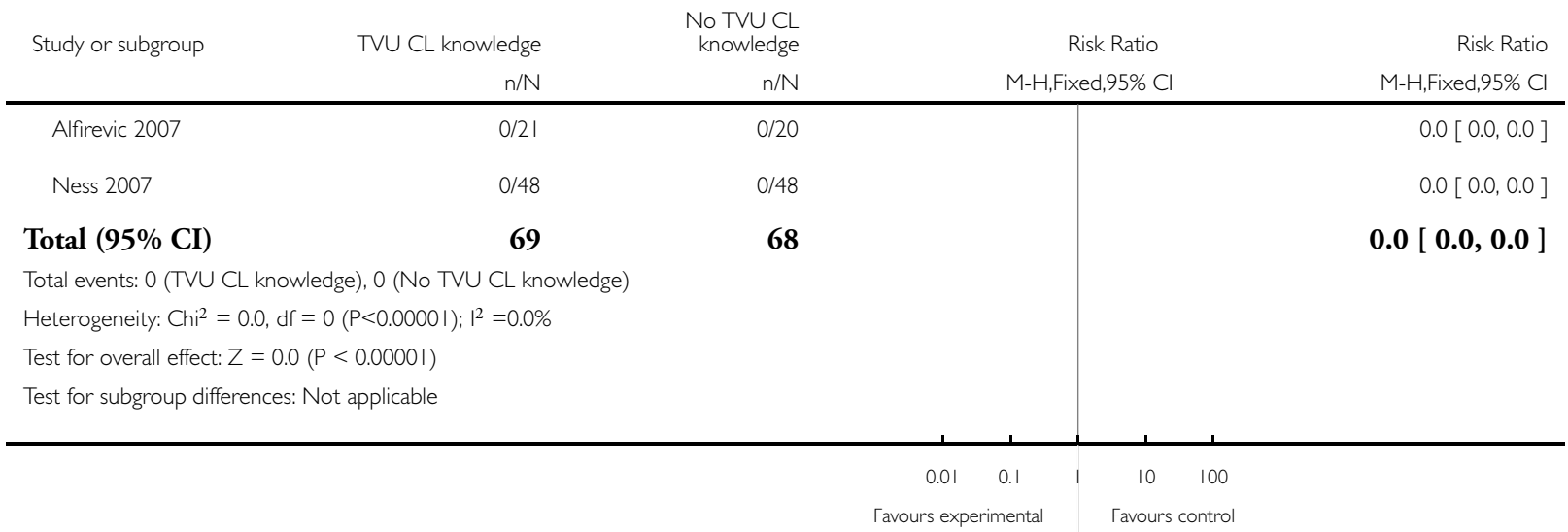


Analysis 2.4. Comparison 2 TVU CL knowledge versus no knowledge (symptomatic singletons with PTL), Outcome 4 gestational age at delivery.

Review: Cervical assessment by ultrasound for preventing preterm delivery

Comparison: 2 TVU CL knowledge versus no knowledge (symptomatic singletons with PTL)

Outcome: 4 gestational age at delivery

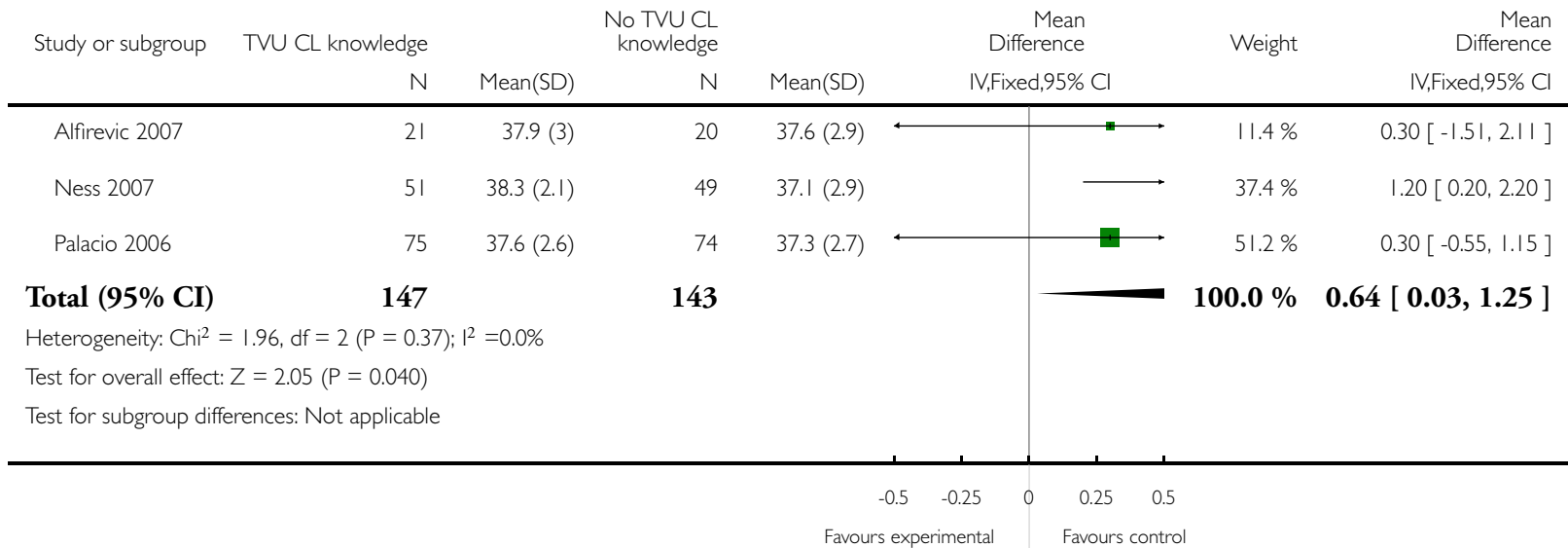

Analysis 2.5. Comparison 2 TVU CL knowledge versus no knowledge (symptomatic singletons with PTL), Outcome 5 Birthweight $<2500$ grams.

Review: Cervical assessment by ultrasound for preventing preterm delivery

Comparison: 2 TVU CL knowledge versus no knowledge (symptomatic singletons with PTL)

Outcome: 5 Birthweight $<2500$ grams

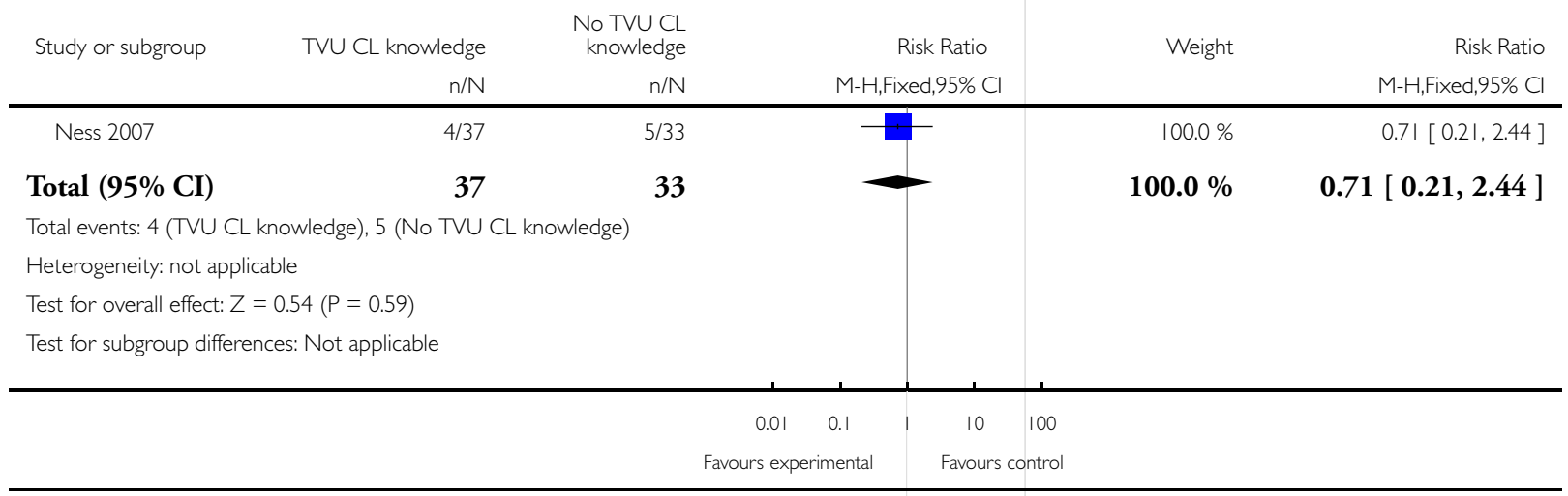

Cervical assessment by ultrasound for preventing preterm delivery (Review)

Copyright $\odot 2013$ The Cochrane Collaboration. Published by John Wiley \& Sons, Ltd. 
Analysis 2.6. Comparison 2 TVU CL knowledge versus no knowledge (symptomatic singletons with PTL), Outcome 6 Perinatal death.

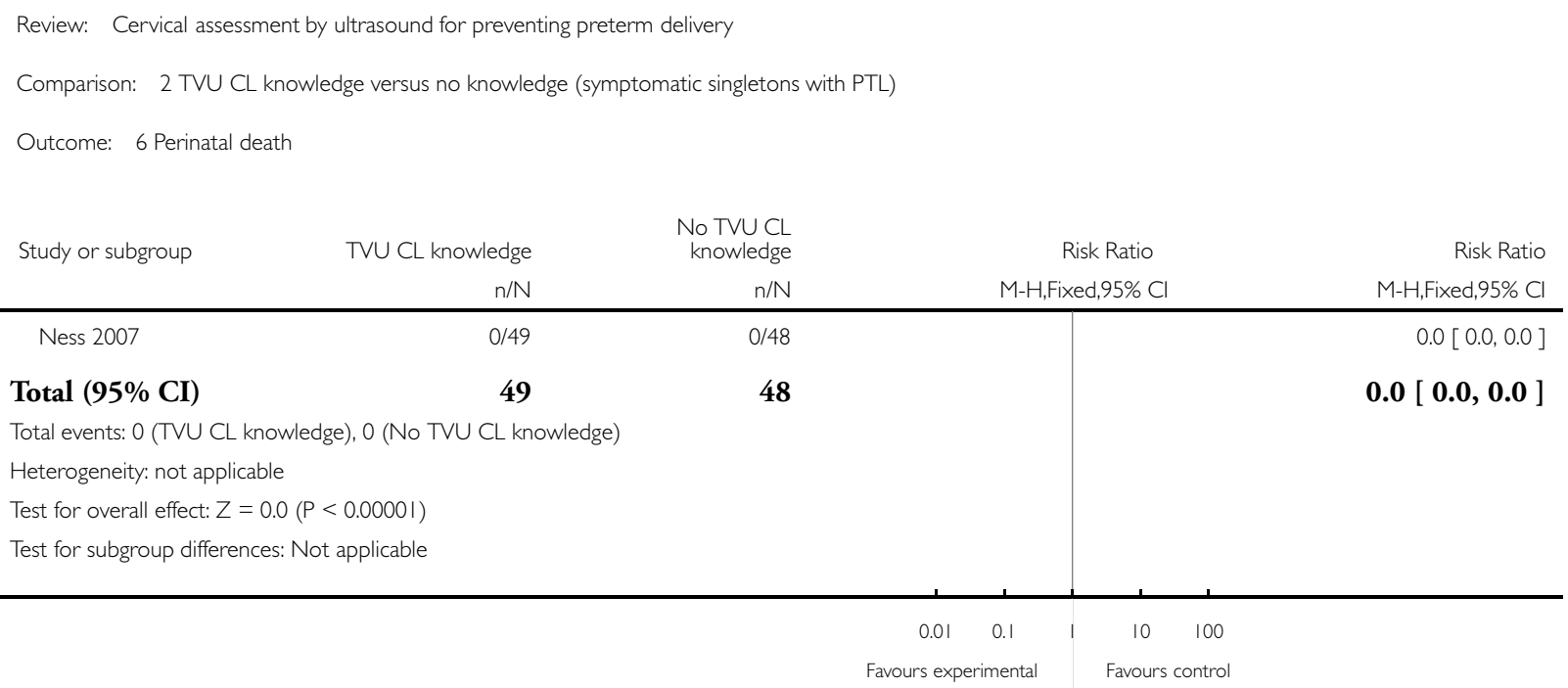


Analysis 2.7. Comparison 2 TVU CL knowledge versus no knowledge (symptomatic singletons with PTL), Outcome 7 Maternal hospitalization.

Review: Cervical assessment by ultrasound for preventing preterm delivery

Comparison: 2 TVU CL knowledge versus no knowledge (symptomatic singletons with PTL)

Outcome: 7 Maternal hospitalization

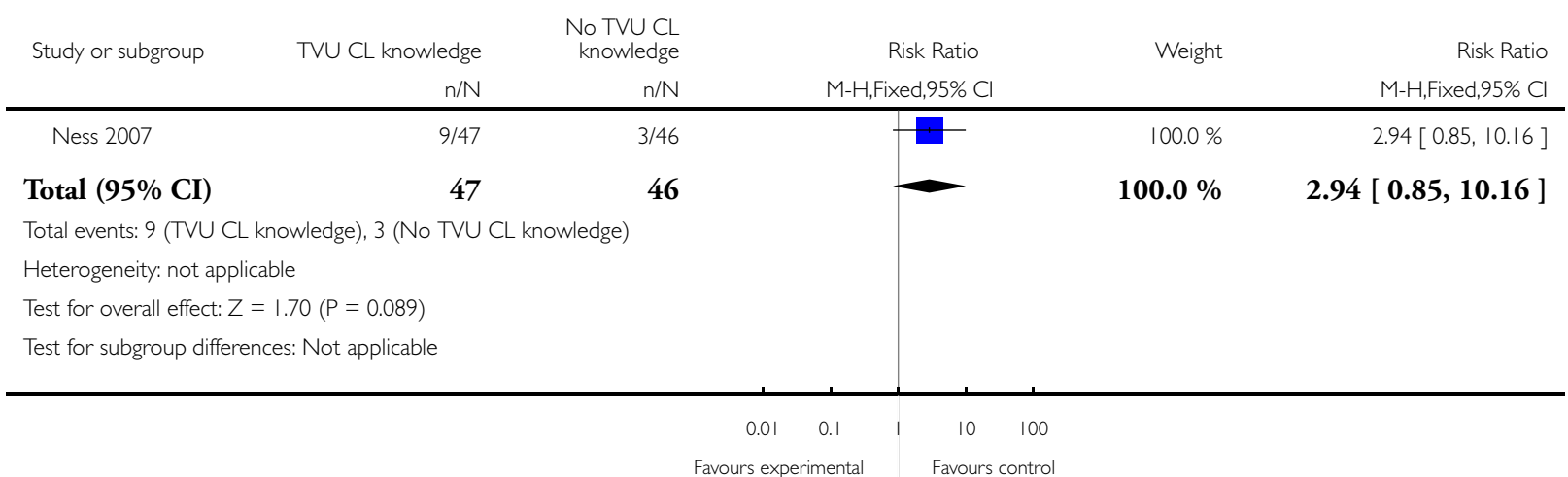

Analysis 2.8. Comparison 2 TVU CL knowledge versus no knowledge (symptomatic singletons with PTL), Outcome 8 Tocolysis.

Review: Cervical assessment by ultrasound for preventing preterm delivery

Comparison: 2 TVU CL knowledge versus no knowledge (symptomatic singletons with PTL)

Outcome: 8 Tocolysis

Study or subgroup

$n / N$

Alfirevic 2007
Ness 2007

Total (95\% CI)

$7 / 21 \quad 20 / 20$

9/39 2/22

$2 / 22$

60

42

Total events: 16 (TVU CL knowledge), 22 (No TVU CL knowledge)

Heterogeneity: $\mathrm{Tau}^{2}=1.89 ; \mathrm{Chi}^{2}=7.00, \mathrm{df}=\mathrm{I}(\mathrm{P}=0.0 \mathrm{I}) ; \mathrm{I}^{2}=86 \%$

Test for overall effect: $Z=0.16(P=0.88)$

Test for subgroup differences: Not applicable

\begin{tabular}{|c|c|c|}
\hline $\begin{array}{c}\text { Risk Ratio } \\
\text { M- } \\
\text { H,Random,95\% } \\
\mathrm{Cl}\end{array}$ & Weight & $\begin{array}{c}\text { Risk Ratio } \\
\text { M- } \\
\text { H,Random,95\% } \\
\mathrm{Cl}\end{array}$ \\
\hline \# & $55.1 \%$ & $0.35[0.19,0.63]$ \\
\hline & $44.9 \%$ & $2.54[0.60,10.72]$ \\
\hline
\end{tabular}


Analysis 2.9. Comparison 2 TVU CL knowledge versus no knowledge (symptomatic singletons with PTL), Outcome 9 Steroids for fetal lung maturity.

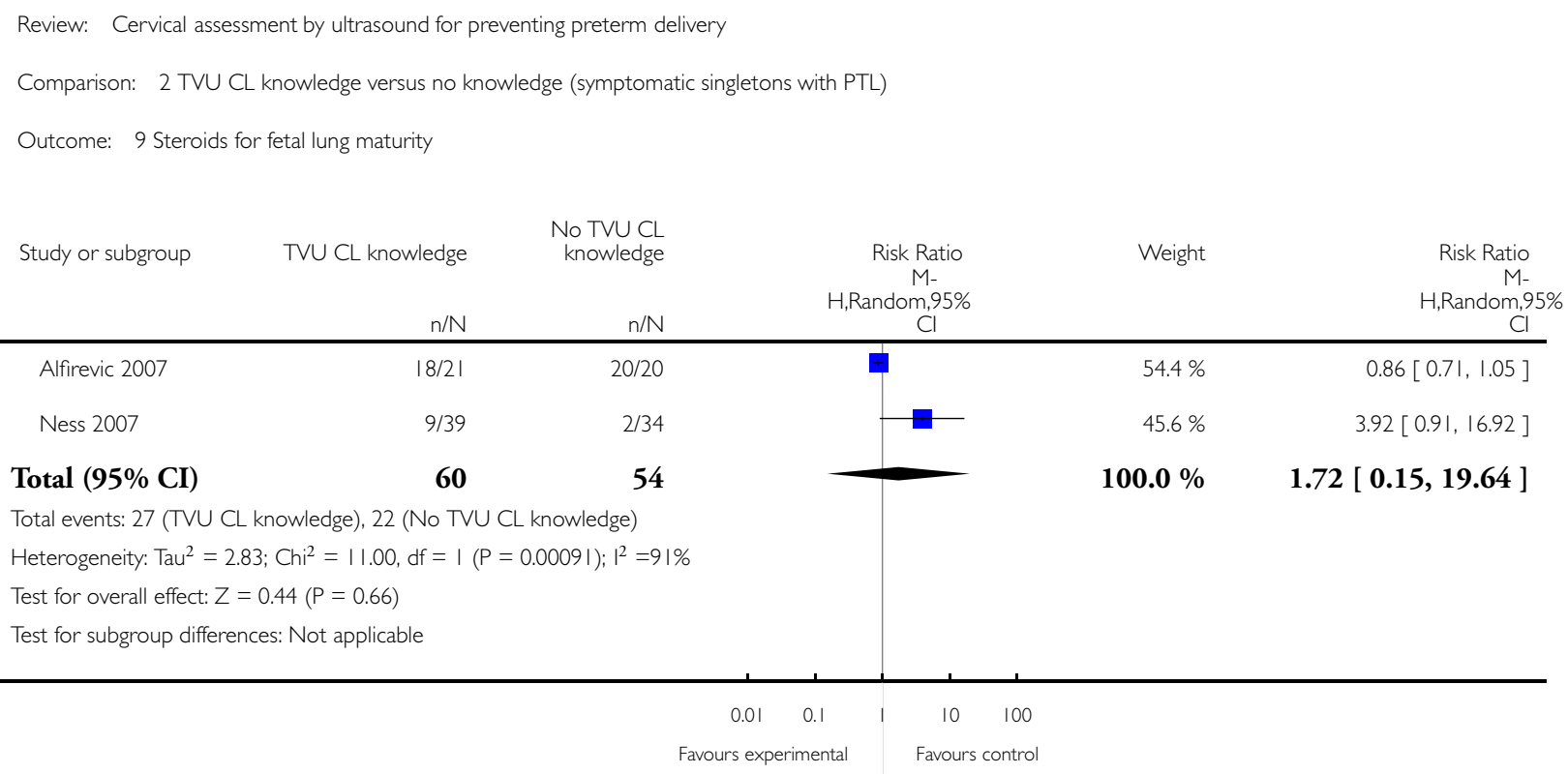


Analysis 3.I. Comparison 3 TVU CL knowledge versus no knowledge (symptomatic singletons with PPROM), Outcome I Birthweight $<2500$ grams.

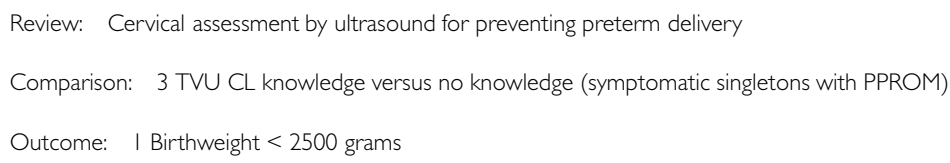

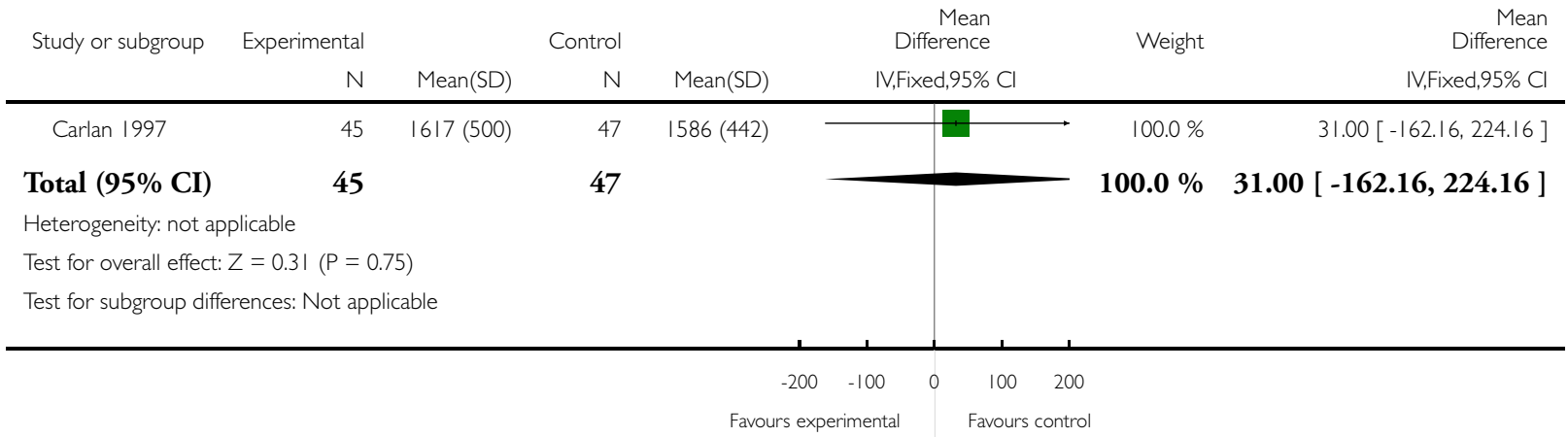

\section{Analysis 3.2. Comparison 3 TVU CL knowledge versus no knowledge (symptomatic singletons with} PPROM), Outcome 2 Chorioamnionitis.

Review: Cervical assessment by ultrasound for preventing preterm delivery

Comparison: 3 TVU CL knowledge versus no knowledge (symptomatic singletons with PPROM)

Outcome: 2 Chorioamnionitis

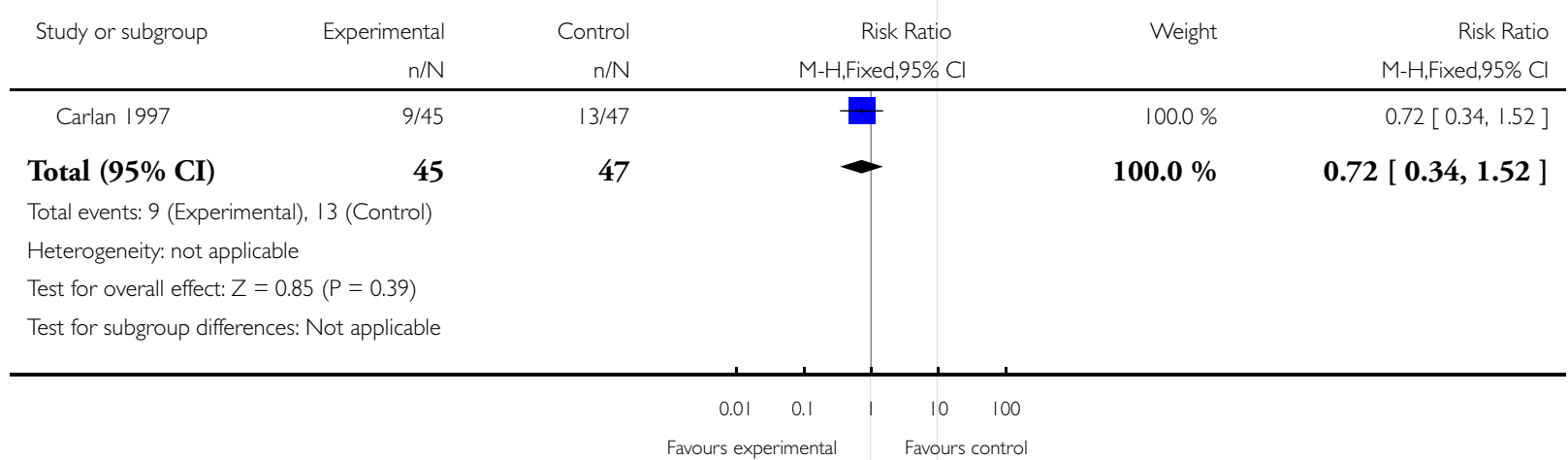


Analysis 3.3. Comparison 3 TVU CL knowledge versus no knowledge (symptomatic singletons with PPROM), Outcome 3 Endometritis.

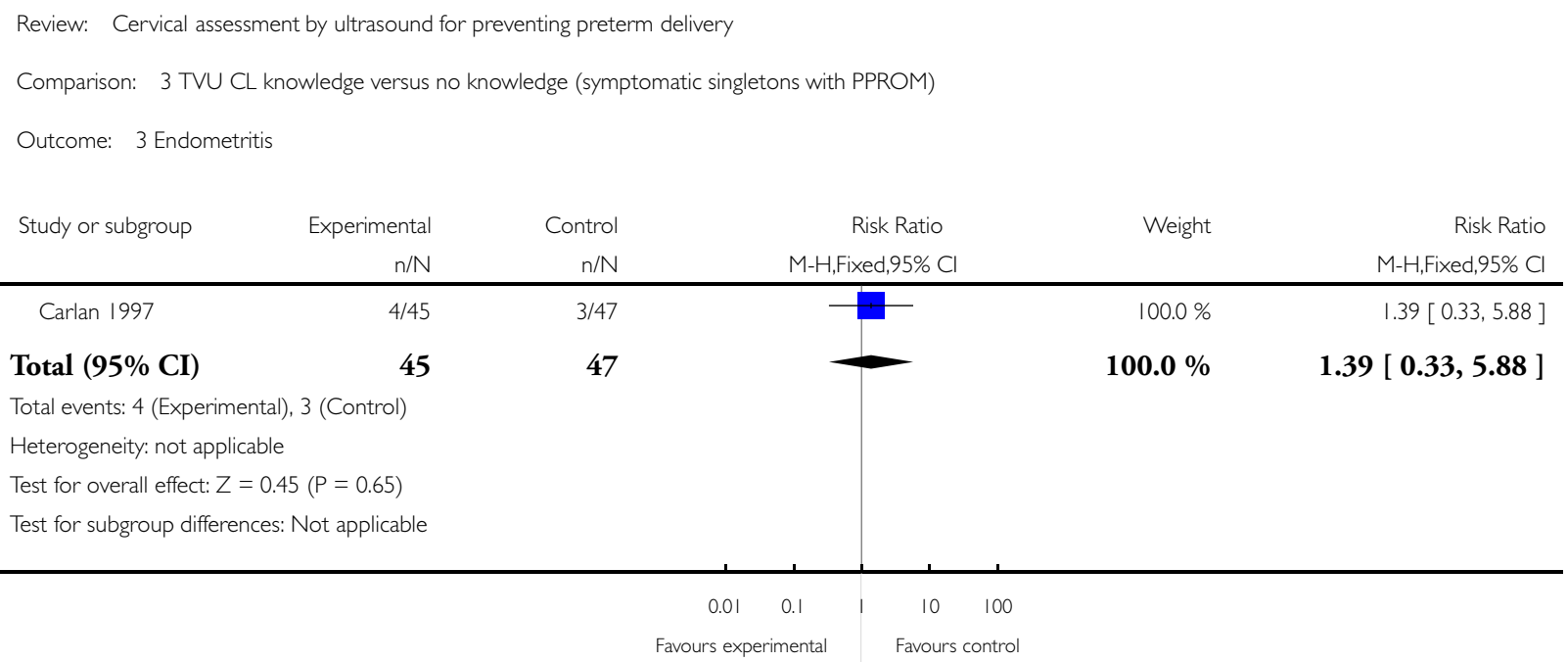

\section{Analysis 3.4. Comparison 3 TVU CL knowledge versus no knowledge (symptomatic singletons with PPROM), Outcome 4 Neonatal infection.}

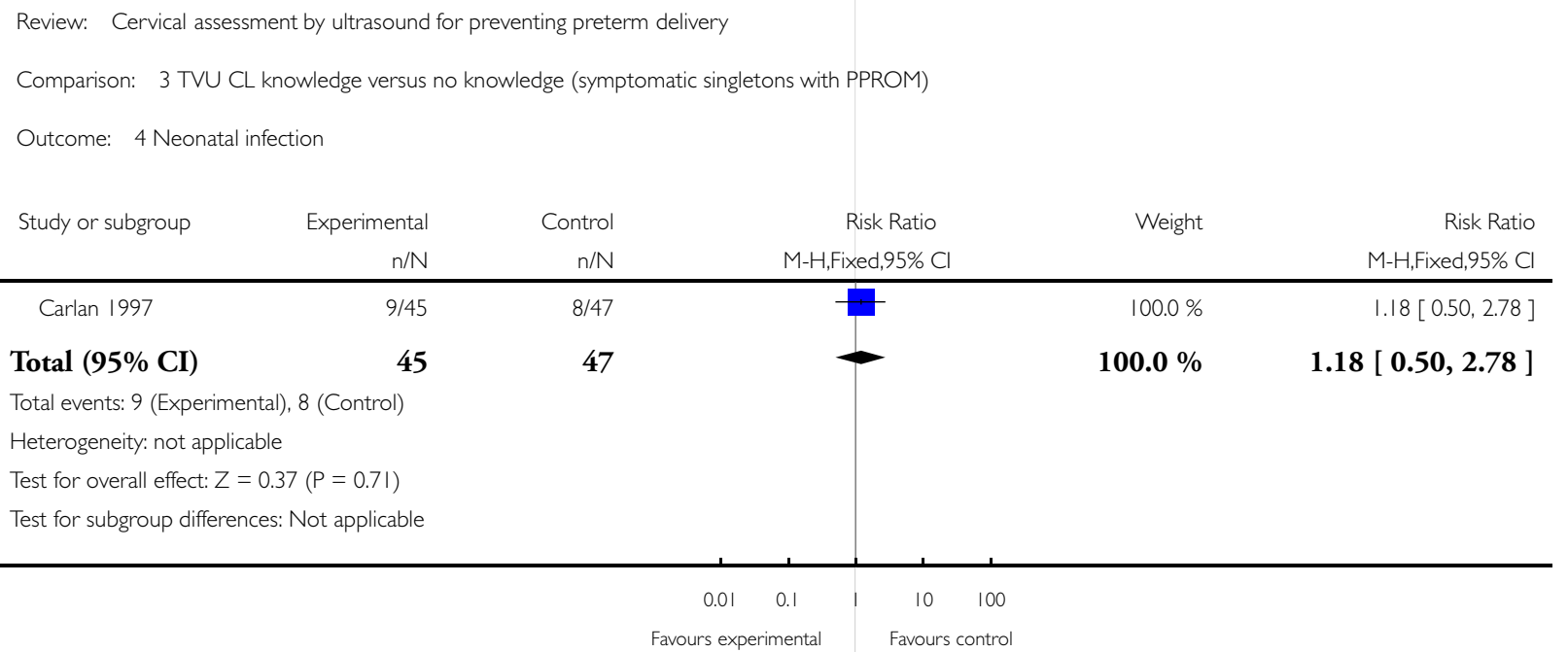




\section{A P P E N D I C E S}

\section{Appendix I. MEDLINE search strategy}

Authors searched MEDLINE (January 1966 to September 2008)

1 exp Ultrasonography, Prenatal/

2 (cervix or cervical or transvaginal\$ or trans-vaginal\$).mp.

3 exp Obstetric Labor, Premature/

41 and 2 and 3

\section{Appendix 2. Methods used when assessing the trials identified in the previous version of this review}

\section{Selection of studies}

We assessed for inclusion all potential studies we identified as a result of the search strategy. Independently, all three review authors (V Berghella (VB), N Hendrix (NH), and JK Baxter (JB)) assessed all studies for inclusion in the review using the inclusion criteria. We resolved any disagreement through discussion.

\section{Data extraction and management}

We designed a form to extract data. Three authors (VB, NH, JB) extracted the data using the agreed form. We resolved any disagreement through discussion. We used the Review Manager software (RevMan 2008) to double enter all the data or a subsample.

When information regarding any of the above was unclear, or to obtain additional data not published, we attempted to contact authors of the original reports to provide further details.

\section{Assessment of risk of bias in included studies}

We have assessed the validity of each study using the criteria outlined in the Cochrane Handbook for Systematic Reviews of Interventions (Higgins 2008). We described the methods used for generation of the randomization sequence for each trial.

\section{(I) Sequence generation (checking for possible selection bias)}

We have described for each included study the method used to generate the allocation sequence in sufficient detail to allow an assessment of whether it should produce comparable groups.

We have assessed the method as:

- adequate (any truly random process e.g. random number table; computer random number generator);

- inadequate (any non-random process e.g. odd or even date of birth; hospital or clinic record number);

- unclear.

\section{(2) Allocation concealment (checking for possible selection bias)}

We described for each included study the method used to conceal the allocation sequence in sufficient detail and determined whether intervention allocation could have been foreseen in advance of, or during recruitment, or changed after assignment. We assessed the methods as:

- adequate (e.g. telephone or central randomization; consecutively numbered sealed opaque envelopes);

- inadequate (open random allocation; unsealed or non-opaque envelopes, alternation; date of birth);

- unclear. 


\section{(3) Blinding (checking for possible performance bias)}

We have described for each included study the methods used, if any, to blind study participants and personnel from knowledge of which intervention a participant received. We have judged studies to be at low risk of bias if they were blinded, or if we judged that the lack of blinding could not have affected the results. We have assessed blinding separately for different outcomes or classes of outcomes. We have assessed the methods as:

- adequate, inadequate, or unclear for participants;

- adequate, inadequate, or unclear for personnel;

- adequate, inadequate, or unclear for outcome assessors.

\section{(4) Incomplete outcome data (checking for possible attrition bias through withdrawals, dropouts, protocol deviations)}

We have described for each included study, and for each outcome or class of outcomes, the completeness of data, including attrition and exclusions from the analysis. We have stated whether attrition and exclusions were reported, the numbers included in the analysis at each stage (compared with the total randomized participants), reasons for attrition or exclusion where reported, and whether missing data were balanced across groups or were related to outcomes. Where sufficient information has been reported, or been supplied by the trial authors, we have re-included missing data in our analyses. We have assessed methods as:

- adequate $(<20 \%)$;

- inadequate $(>=20 \%)$;

- unclear.

\section{(5) Selective reporting bias}

We have described for each included study how we investigated the possibility of selective outcome reporting bias and what we found. We have assessed the methods as:

- adequate (where it is clear that all of the study's prespecified outcomes and all expected outcomes of interest to the review have been reported);

- inadequate (where not all the study's prespecified outcomes have been reported; one or more reported primary outcomes were not prespecified; outcomes of interest are reported incompletely and so cannot be used; study fails to include results of a key outcome that would have been expected to have been reported);

- unclear

\section{WHAT'S NEW}

Last assessed as up-to-date: 28 November 2012.

Date Event Description

28 January 2013 Amended Information added on attrition bias for one study (Ness 2007). 


\section{H I S T O R Y}

Protocol first published: Issue 3, 2008

Review first published: Issue 3, 2009

\begin{tabular}{|c|c|c|}
\hline Date & Event & Description \\
\hline 26 September 2012 & $\begin{array}{l}\text { New citation required but conclusions have not } \\
\text { changed }\end{array}$ & Review updated. \\
\hline 26 September 2012 & New search has been performed & $\begin{array}{l}\text { Two studies identified from an updated search have } \\
\text { been assessed for eligibility and both have been ex- } \\
\text { cluded. Methods have been updated }\end{array}$ \\
\hline 27 January 2012 & Amended & $\begin{array}{l}\text { Search updated. Two trial reports added to Studies } \\
\text { awaiting classification (Burwick 2011; Simcox 2009). }\end{array}$ \\
\hline
\end{tabular}

\section{CONTRIBUTIONSOFAUTHORS}

Vincenzo Berghella devised the idea, applied for the review, wrote the draft of the review and approved the final edition. Jason K Baxter, Nancy Hendrix edited and approved the final review, and performed review and analysis of pertinent and included studies.

\section{DECLARATIONSOF INTEREST}

One of the authors of this Cochrane Review (Vincenzo Berghella) is a co-author on one of the included trials (Ness 2007).

\section{SOURCES OF SUPPORT}

\section{Internal sources}

- No sources of support supplied

\section{External sources}

- National Institute for Health Research, UK.

NIHR Programme of centrally-managed pregnancy and childbirth systematic reviews of priority to the NHS and users of the NHS: 10/4001/02 


\section{DIFFERENCES BETWEEN PROTOCOLANDREVIEW}

A number of outcomes not prespecified in the protocol were included in the review, as listed below.

1. Preterm birth (less than 36 weeks) (outcome not prespecified)

2. Preterm birth (less than 30 weeks) (outcome not prespecified)

3. Birthweight (outcome not prespecified)

4. Neonatal infection (outcome not prespecified)

5. Chorioamnionitis (outcome not prespecified)

6. Endometritis (outcome not prespecified)

\section{INDEX TERMS}

\section{Medical Subject Headings (MeSH)}

Cervical Length Measurement [ ${ }^{*}$ methods]; Cervix Uteri [*ultrasonography]; Pregnancy, Multiple; Pregnancy, Twin; Premature Birth [* prevention \& control; ultrasonography]; Randomized Controlled Trials as Topic

\section{MeSH check words}

Female; Humans; Pregnancy 